\title{
Regional anesthesia to ameliorate postoperative analgesia outcomes in pediatric surgical patients: an updated systematic review of randomized controlled trials
}

This article was published in the following Dove Press journal:

Local and Regional Anesthesia

\author{
Mark C Kendall' \\ Lucas J Castro Alves ${ }^{2}$ \\ Edward I Suh' \\ Zachary L McCormick ${ }^{3}$ \\ Gildasio S De Oliveira' \\ 'Department of Anesthesiology, \\ Rhode Island Hospital, The Warren \\ Alpert Medical School of Brown \\ University, Providence, RI, USA; \\ ${ }^{2}$ Department of Anesthesiology, Sao \\ Paulo State University, Sao Paulo, \\ Brazil; ${ }^{3}$ Division of Physical Medicine \\ and Rehabilitation, University of Utah, \\ Salt Lake City, UT, USA
}

\begin{abstract}
Regional anesthesia is becoming increasingly popular among anesthesiologists in the management of postoperative analgesia following pediatric surgery. The main objective of this review was to systematically evaluate the last 5 years of randomized controlled trials on the role of regional anesthesia techniques in alleviating postoperative pain associated with various pediatric surgical procedures. Forty studies on 2,408 pediatric patients were evaluated. The majority of the articles published from 2013 to 2017 reported that the use of regional anesthesia minimized postoperative pain and reduced opioid consumption. Only a few surgical procedures (cholecystectomy, inguinal hernia repair, and non-laparoscopic major abdominal surgery) reported no significant difference in the postoperative pain relief compared with the standard anesthetic management. The growing number of randomized controlled trials in the pediatric literature is very promising; however, additional confirmation is needed to reinforce the use of specific regional anesthesia techniques to provide optimal postoperative pain relief for a few surgical procedures (reconstructive ear surgery, chest wall deformity, hypospadias, umbilical hernia, cleft palate repair) in pediatric patients. More randomized controlled trials are needed to establish regional anesthesia as an essential component of postoperative analgesia management in children.
\end{abstract}

Keywords: regional anesthesia, peripheral nerve block, pediatrics

\section{Introduction}

Postoperative pain remains poorly treated in the general surgical population. ${ }^{1,2}$ Specifically in pediatric patients, few clinical trials have evaluated the efficacy of non-opioid analgesic interventions for improving post-surgical analgesic outcomes. ${ }^{3-5}$ The lack of established efficacy for multimodal analgesic interventions in pediatric patients can result in an increased use of opioid medications in the postoperative period. ${ }^{6-8}$ Postsurgical pain is the most common medical encounter associated with opioid prescriptions. ${ }^{9}$ As such, the current call to decrease the use of prescription opioids makes the evaluation of multimodal analgesia (ie, regional anesthesia) in pediatric surgery a very timely topic in perioperative medicine. ${ }^{10,11}$

Among the different multimodal analgesic strategies, the use of regional anesthesia has substantially increased in pediatric patients. ${ }^{12-14}$ The use of ultrasonography to assist anesthesiologists in the placement of regional nerve blocks may contribute to the increase in the use of regional anesthesia in children. ${ }^{15-17}$ The proliferation of large database studies demonstrating the safety of regional anesthesia in children has
Correspondence: Mark C Kendall Island Hospital, The Warren Alpert Medical School of Brown University, 593 Eddy Street, Providence, RI 02903, USA

$\mathrm{Tel}+\mathrm{I}$ 40I 4444933

Fax + I 4014445090

Email mark.kendall@lifespan.org 
supported the increased use of this technique. ${ }^{18-20}$ Our group has previously performed a qualitative systematic review to assess the efficacy of regional anesthesia in reducing postoperative pain for pediatric patients. ${ }^{21}$ However, many randomized studies have been published since that review, and this more recent knowledge has yet to be evaluated.

The primary goal of the current systematic review was to evaluate the use of regional anesthesia to improve postoperative analgesia in pediatric patients. In addition, we wanted to identify complications associated with regional anesthesia in the same population.

\section{Methods}

We followed the same methods previously used in our first qualitative systematic review in order to update the results. ${ }^{21}$ We performed a systematic review in accordance with the PRISMA guidelines. ${ }^{22}$

\section{Systematic search}

Articles of randomized controlled trials exploring regional anesthesia on postoperative pain in pediatric patients were searched using the PubMed database, Google Scholar, and the Cochrane Database of Systematic Reviews, from May 22, 2013, to December 31, 2017. Our prior review included studies up to May 21, 2013. Free text and MeSH terms "regional," "blocks," "pain," "surgery," "post-operative," "opioid," and "analgesia" were used individually and in a variety of combinations. The inquiry was limited to human subjects younger than 18 years of age. An attempt to identify additional studies that were not found by the primary search methods was achieved by reviewing the reference lists from the identified studies. No restrictions on language were used. There was no search performed for unpublished studies. This initial search yielded 1,552 manuscripts.

\section{Selection of included studies}

The inclusion and exclusion criteria were determined in advance before the commencement of the systematic review. Two trained authors (MCK and LJCA) independently evaluated the abstract and results of the 1,552 articles obtained by the primary search. Articles were excluded if they were clearly not pertinent to our inclusion and exclusion criteria. Disagreements on inclusion of the articles were resolved by discussion among the evaluators, and if consensus was not met, then the final decision was determined by the assistance of a third investigator (GSDO) who was blinded regarding the evaluation of the first two authors. The filtered search subsequently resulted in 123 articles.

\section{Inclusion and exclusion criteria}

We included randomized controlled trials that compared perioperative regional blocks with local anesthetics and a control group in pediatric patients undergoing various surgical procedures. Trials containing a concurrent use of an alternative multimodal analgesia regimen were rejected if a direct comparison between a regional anesthesia technique and a control could not be determined. Studies that provided a direct comparison between two different regional anesthetic techniques, two different local anesthetics, and/or comparisons involving a block adjunct were included. The trials included in the review had to report on postoperative pain outcomes such as pain scores or opioid consumption. There was no limitation on sample size in the systematic review.

\section{Validity scoring}

Two authors (MCK and LJCA) independently reviewed the included articles and assessed their quality using the modified Jadad five-point scale. ${ }^{23}$ The Jadad scale evaluates a study using the following criteria: randomization, valid randomization method, double-blind evaluation, concealment of the study group to an evaluator, and completeness of data at follow-up. Disagreements in scoring were resolved by discussion among the evaluators, and if a consensus was not met, then the final decision was determined by the assistance of a third investigator (GSDO). The minimum score of an included randomized trial was 1 and the maximum score was 5. No studies were ruled out based on quality assessment scores.

\section{Data extraction}

Two authors (MCK and LJCA) independently evaluated the full manuscripts of all included trials and performed data extraction using a data collection form specifically developed for this review. Discrepancies were resolved by discussion among the evaluators, and if consensus was not met, then the final decision was made by the third investigator (GSDO). The data obtained from the trials included nerve block type, sample size, the local anesthetic type and dose, use of ultrasonography, number of patients in treatment groups, type of surgery, early ( $\leq 4$ hour) postoperative pain scores and late (24 hours) postoperative pain scores at rest, cumulative opioid consumption, time to rescue analgesic administration (minutes), follow-up period, and adverse events.

\section{Definition of outcome data}

\section{Primary outcomes}

Early postoperative pain scores at rest (4 hours after operation); late postoperative pain scores (24 hours after 
operation); and cumulative opioid consumption (24 hours) in the postoperative period.

\section{Secondary outcomes}

The time to first analgesic administration (minutes) and adverse events including but not limited to: postoperative hypotension, nerve damage, and local anesthetic toxicity.

\section{Meta-analyses}

Because the study comparisons were clinically nonhomogeneous and the number of studies with similar comparisons was small (less than three studies), a qualitative description of outcomes was considered more appropriate to assess the included studies. We therefore did not explore the presence of publication bias as we have done in our previous studies. ${ }^{24-26}$

\section{Results}

Our search identified 123 articles and we evaluated 40 studies on 2,408 pediatric patients undergoing various surgical procedures (Figure 1). ${ }^{27-66}$ The median (interquartile range) of the sample size for included studies was 60 (40-70) and the Jadad score was 4 (2-5). Articles that did not meet the inclusion criteria upon further evaluation of full text were omitted $^{67-113}$ and they included incomplete data on analgesic

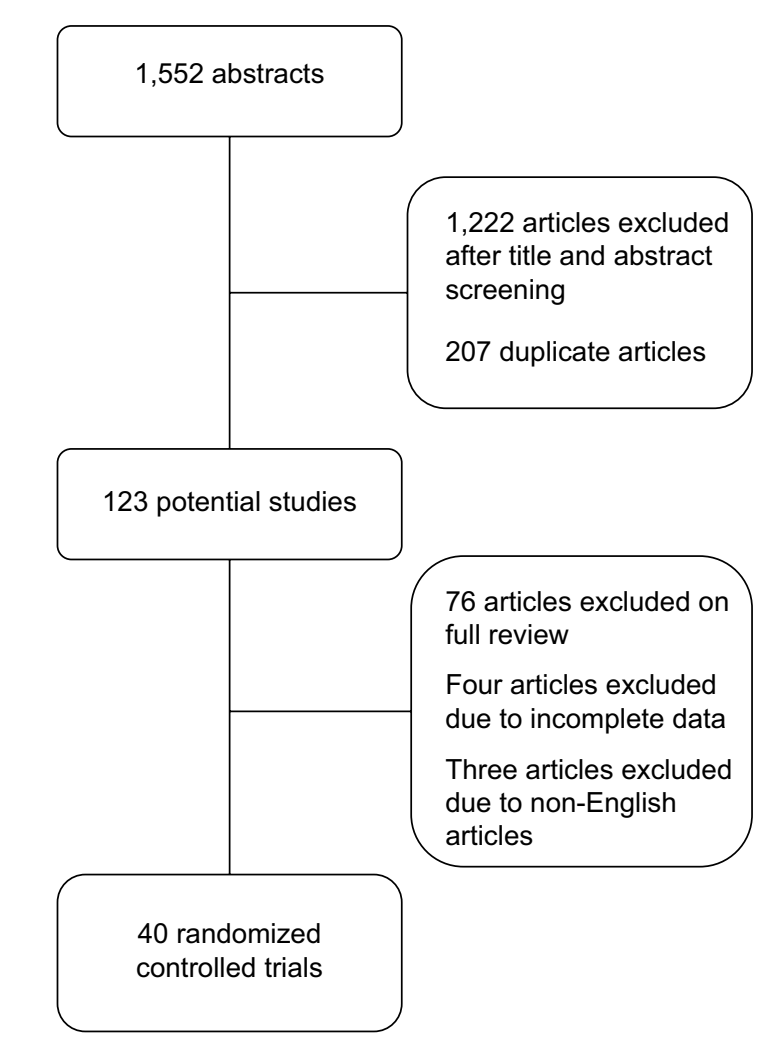

Figure I Flow chart outlining systematic review of randomized controlled trials. outcomes, ${ }^{114-117}$ age limit exceeded, ${ }^{118-181}$ trials involving dental procedures, ${ }^{182-186}$ and non-translated articles. ${ }^{187-189}$ The characteristics of the included trials are presented in Table 1.

\section{Appendectomy}

One study investigated the use of ultrasound-guided rectus sheath block compared with placebo on postoperative pain scores and opioid consumption. ${ }^{53}$ The children who received a rectus sheath block reported significantly lower pain scores compared with the control in the first 3 hours following surgery. However, there was no difference in pain scores between groups after 3 hours. Opioid consumption was not different among groups.

\section{Cholecystectomy}

One study reported the use of regional anesthesia compared with local anesthetic infiltration at laparoscopic port sites in children scheduled to undergo cholecystectomy. ${ }^{58}$ Intraoperative opioid requirements were less in children receiving the bilateral paravertebral block (PVB) than those who received local anesthetic at the port insertions points. Total postoperative hydromorphone patient-controlled analgesia (PCA) consumption and mean pain scores were no different among groups at 12 hours following surgery. The amount of PCA hydromorphone consumption at 8-12 hours following surgery was greater in the PVB group than in the port infiltration group. At 24 hours, pain scores were greater in the PVB group compared with the port infiltration group. The authors did report that the occurrence of shoulder pain was less pronounced $(49 \%, 95 \%$ CI $0.269-0.893)$ in the PVB group compared with the port infiltration group. Although there were two patients who experienced vascular punctures, none of the incidents presented as symptoms of local toxicity.

\section{Circumcision}

Two studies investigated a commonly performed regional anesthesia technique for male circumcision: dorsal penile block. In one study, the authors assessed the analgesic effect of clonidine with bupivacaine in dorsal penile blocks compared with bupivacaine alone. ${ }^{39}$ Children allocated to the clonidine group requested less additional analgesia compared with control. The Children's Hospital of Eastern Ontario Pain Scale (CHEOPS) score was significantly less in the clonidine group until 24 hours after surgery. In the other study, the authors evaluated a multimodal regimen consisting of a ring block, a eutectic mixture of local anesthetic (EMLA) cream, oral sucrose, and a dorsal penile nerve block. ${ }^{35}$ The Neonatal Infant Pain Scale (NIPS) score was significantly lower in 


\begin{tabular}{|c|c|c|c|c|c|c|c|c|c|c|c|c|c|}
\hline 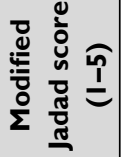 & $\sigma$ & $m$ & $\sigma$ & N & in & in & |n & - & in & $m$ & t & N & $m$ \\
\hline 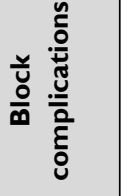 & $\frac{\stackrel{0}{0}}{2}$ & 䢧 & 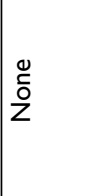 & $\frac{\mathscr{0}}{0}$ & 亗 & 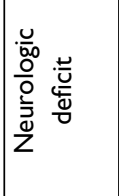 & $\mid \stackrel{0}{0}$ & 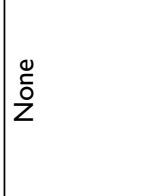 & 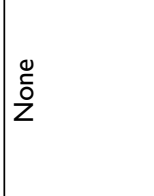 & 兽 & $\mid \stackrel{0}{0}$ & 造 & $\begin{array}{l}0 \\
\text { Z̃ } \\
\text { ż }\end{array}$ \\
\hline 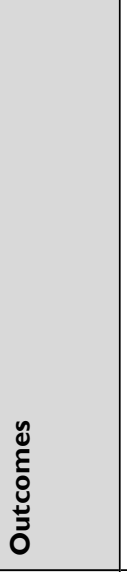 & 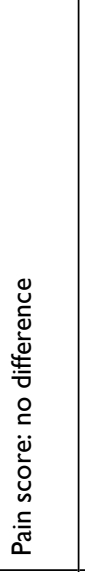 & 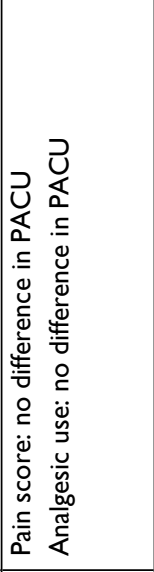 & 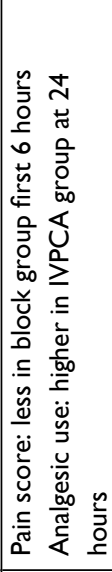 & 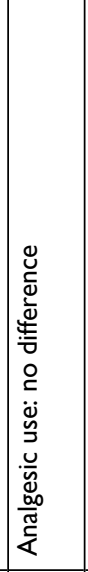 & 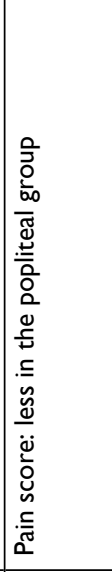 & 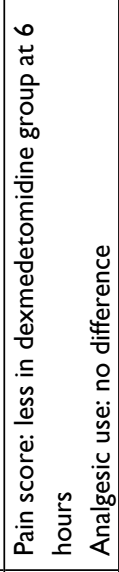 & 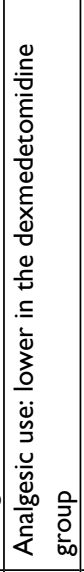 & 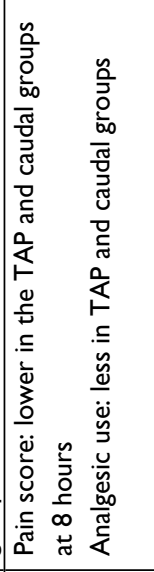 & 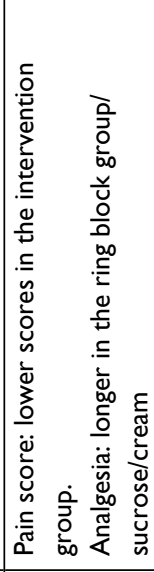 & 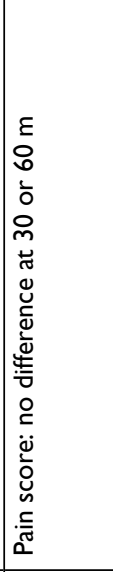 & 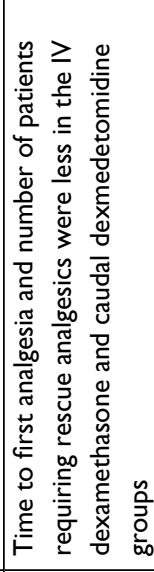 & 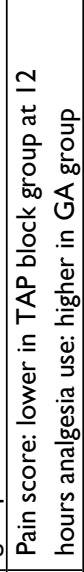 & 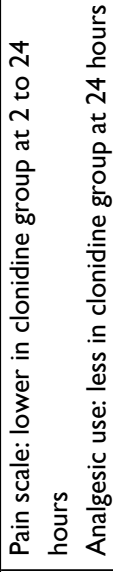 \\
\hline 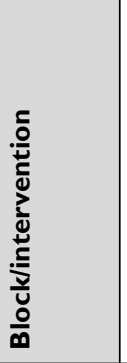 & 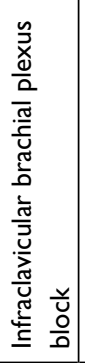 & 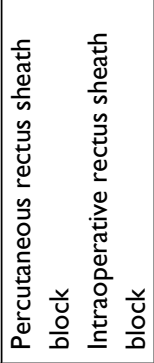 & 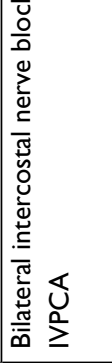 & 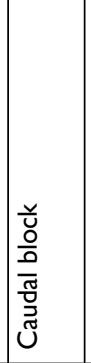 & 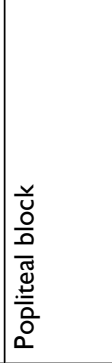 & 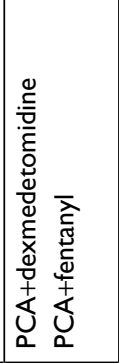 & 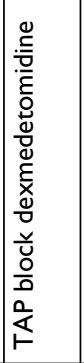 & 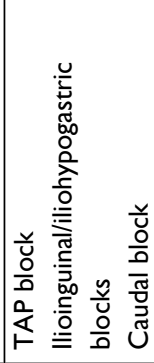 & 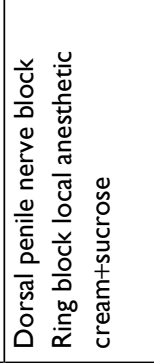 & 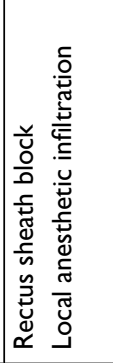 & 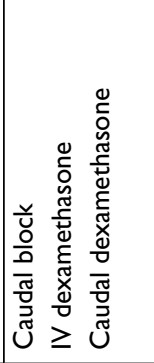 & 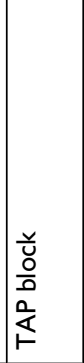 & 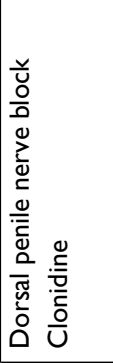 \\
\hline 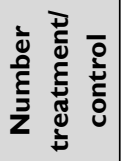 & 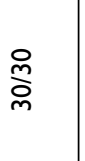 & $\bar{m}$ & $\begin{array}{l}\underset{\sim}{\sim} \\
\underset{m}{f}\end{array}$ & $\frac{\bar{a}}{\frac{0}{a}}$ & 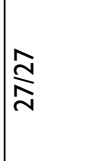 & 帝 & 帝 & 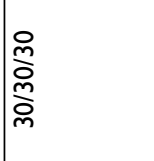 & 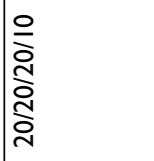 & $\stackrel{\widehat{N}}{\underline{\Sigma}}$ & 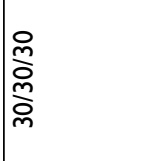 & 旁 & ্ָ \\
\hline Uू & $\succ$ & $\succ$ & $\succ$ & $\succ$ & $\succ$ & $\succ$ & $\succ$ & $\succ$ & $\succ$ & $\succ$ & $z$ & $\succ$ & $z$ \\
\hline 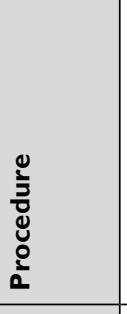 & 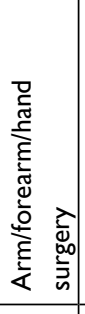 & 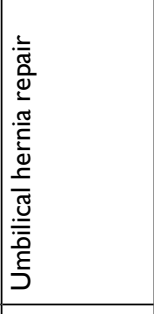 & 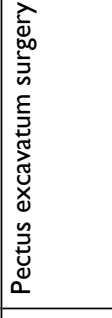 & 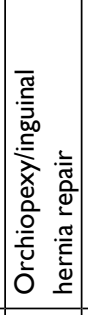 & 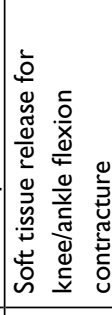 & 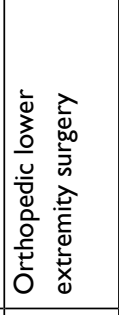 & 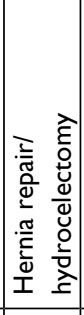 & 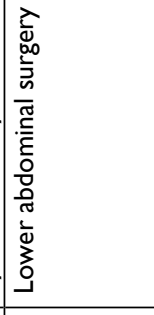 & 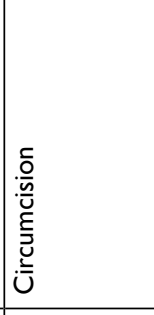 & 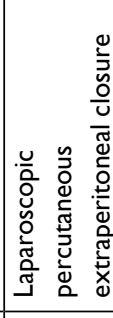 & 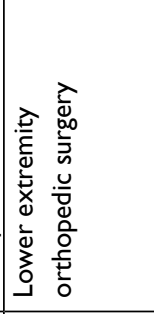 & 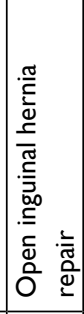 & 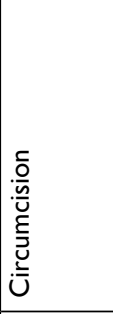 \\
\hline ટ હ & $\bar{i}$ & 호 & $\overline{\mathrm{N}}$ & $\bar{i}$ & $\bar{i}$ & $\bar{i}$ & $\frac{\hat{i}}{i}$ & $\bar{i}$ & $\overline{\text { ¿ }}$ & $\sqrt{\bar{N}}$ & $\frac{0}{2}$ & $\frac{0}{2}$ & $\frac{0}{2}$ \\
\hline $\begin{array}{l}\frac{1}{2} \\
\frac{c}{4} \\
\frac{1}{2} \\
\end{array}$ & 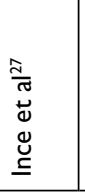 & 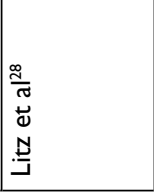 & $\begin{array}{l}\frac{1}{\sqrt{3}} \\
\stackrel{\Xi}{0} \\
\stackrel{9}{コ} \\
\end{array}$ & 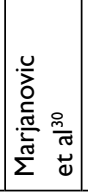 & 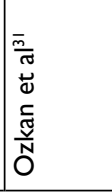 & 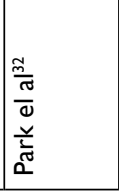 & 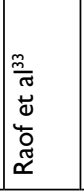 & 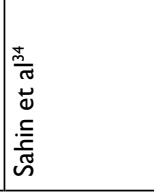 & 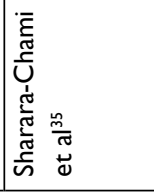 & 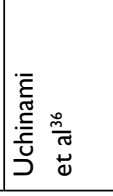 & 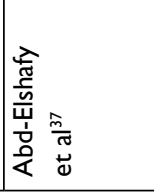 & 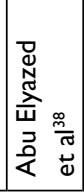 & 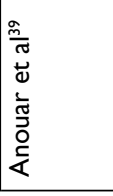 \\
\hline
\end{tabular}




\begin{tabular}{|c|c|c|c|c|c|c|c|c|c|c|c|c|c|}
\hline$m$ & $\sim$ & in & $\sim$ & $\sim$ & in & $m$ & $N$ & $\sim$ & $m$ & $\sigma$ & in & in & in \\
\hline 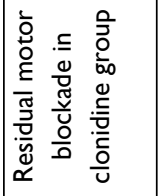 & $\begin{array}{l}0 \\
\text { ¿ू } \\
\text { Z }\end{array}$ & $\begin{array}{l}0 \\
\text { L̃ } \\
\text { ż }\end{array}$ & 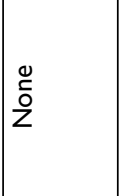 & 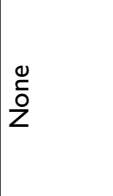 & 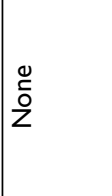 & 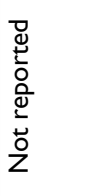 & 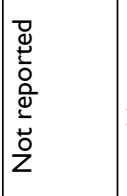 & 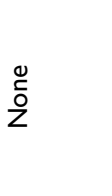 & $\begin{array}{l}0 \\
\text { Õ } \\
\text { ż }\end{array}$ & $\mid \begin{array}{l}0 \\
\tilde{0} \\
z\end{array}$ & $\mid \begin{array}{l}0 \\
\text { ż } \\
z\end{array}$ & 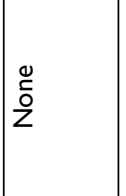 & 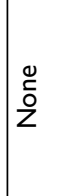 \\
\hline 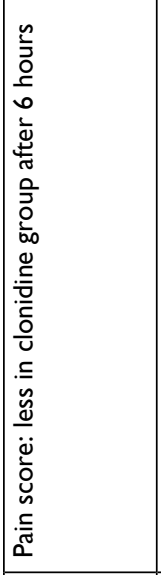 & 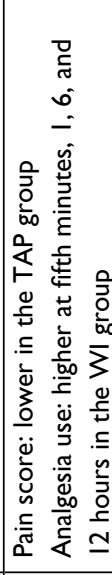 & 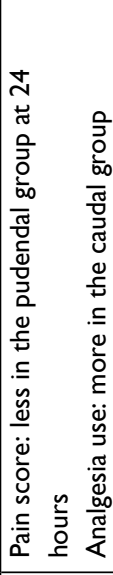 & 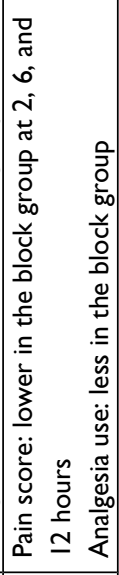 & 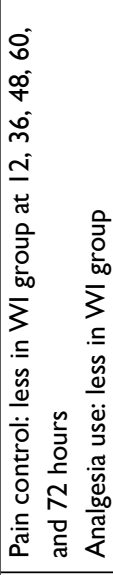 & 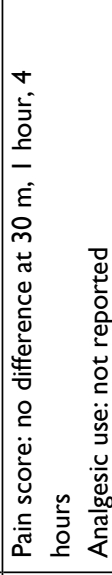 & 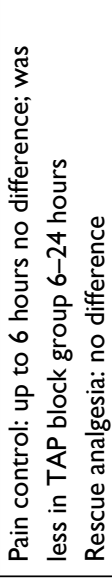 & 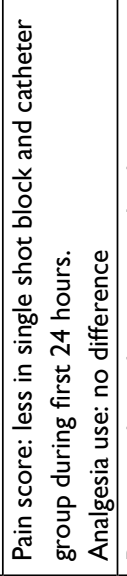 & 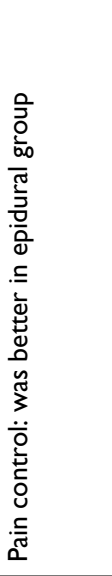 & 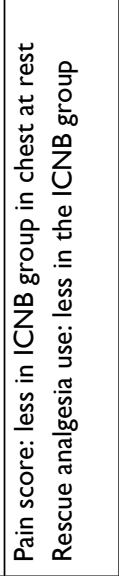 & 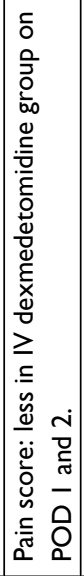 & 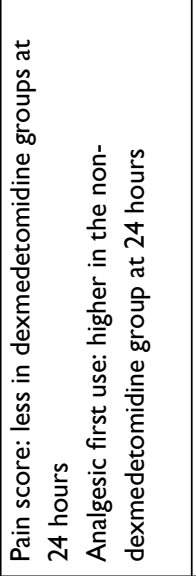 & 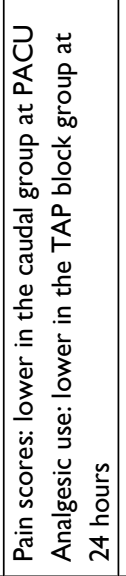 & 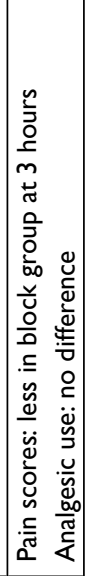 \\
\hline 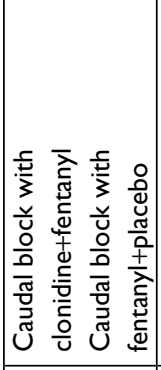 & 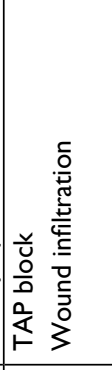 & 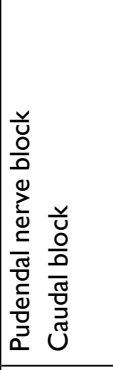 & 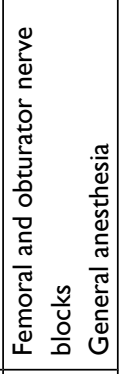 & 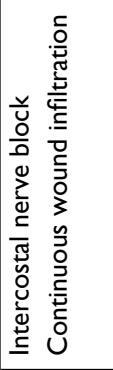 & 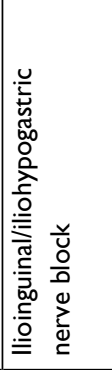 & 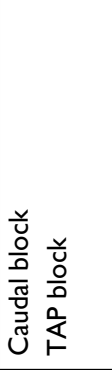 & 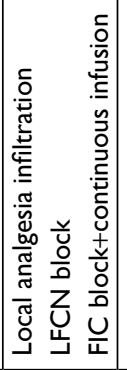 & 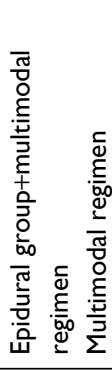 & 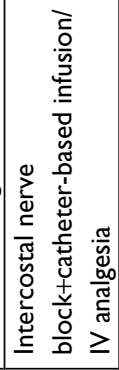 & 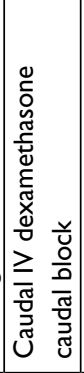 & 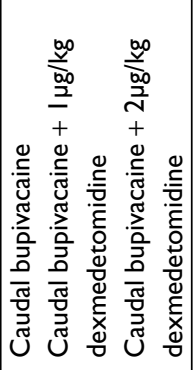 & 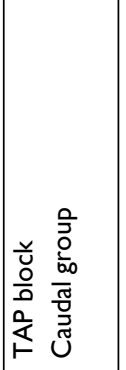 & 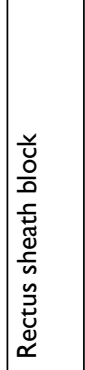 \\
\hline స్సి & స్సి & $\frac{d}{\frac{d}{d}}$ & 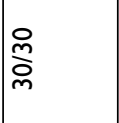 & 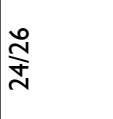 & ్ㅗ & 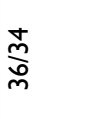 & $\frac{\widehat{N}}{\mathrm{~N}}$ & 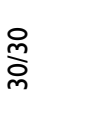 & స్లి & 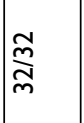 & 爰 & $\mid \overline{\mathcal{N}}$ & $\frac{m}{N}$ \\
\hline$z$ & $\succ$ & $z$ & $\succ$ & $z$ & $\succ$ & $\succ$ & $\succ$ & $z$ & $\succ$ & z & $z$ & $\succ$ & $\succ$ \\
\hline 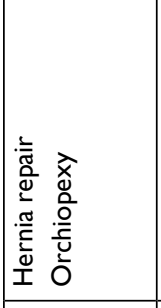 & 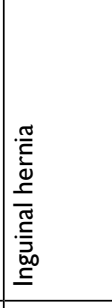 & 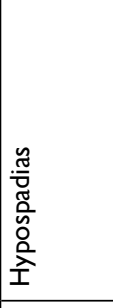 & 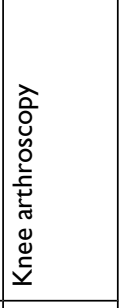 & 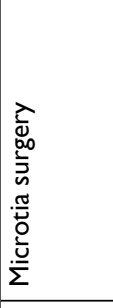 & 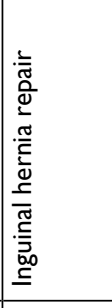 & 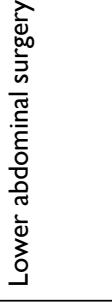 & 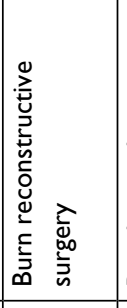 & 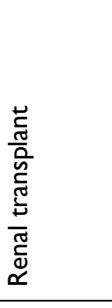 & 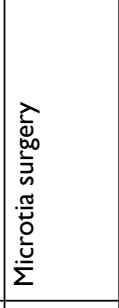 & 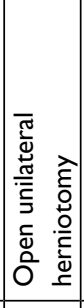 & 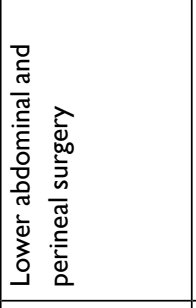 & 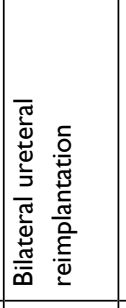 & 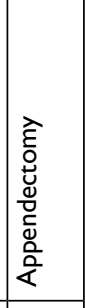 \\
\hline$\frac{0}{2}$ & $\frac{0}{2}$ & $\stackrel{\circ}{2}$ & $\frac{0}{2}$ & $\stackrel{\circ}{2}$ & $\stackrel{\sim}{\circ}$ & $\stackrel{\circ}{\stackrel{\circ}{2}}$ & $\frac{0}{2}$ & $\stackrel{\circ}{\stackrel{\circ}{2}}$ & $\frac{0}{2}$ & $\frac{n}{2}$ & $\frac{\text { nn }}{\mathbf{D}}$ & $\frac{n}{\infty}$ & $\frac{n}{2}$ \\
\hline 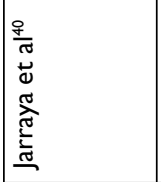 & 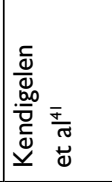 & 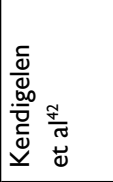 & 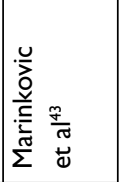 & 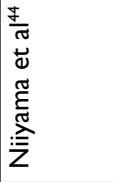 & 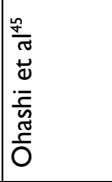 & 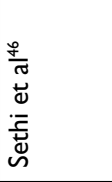 & 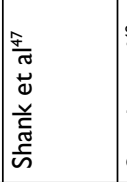 & 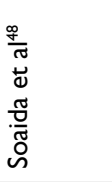 & $\mid \begin{array}{l}\frac{\partial}{2} \\
\frac{\partial}{0} \\
0 \\
0 \\
0 \\
3\end{array}$ & 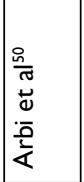 & 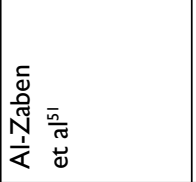 & 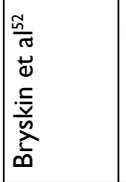 & 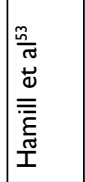 \\
\hline
\end{tabular}




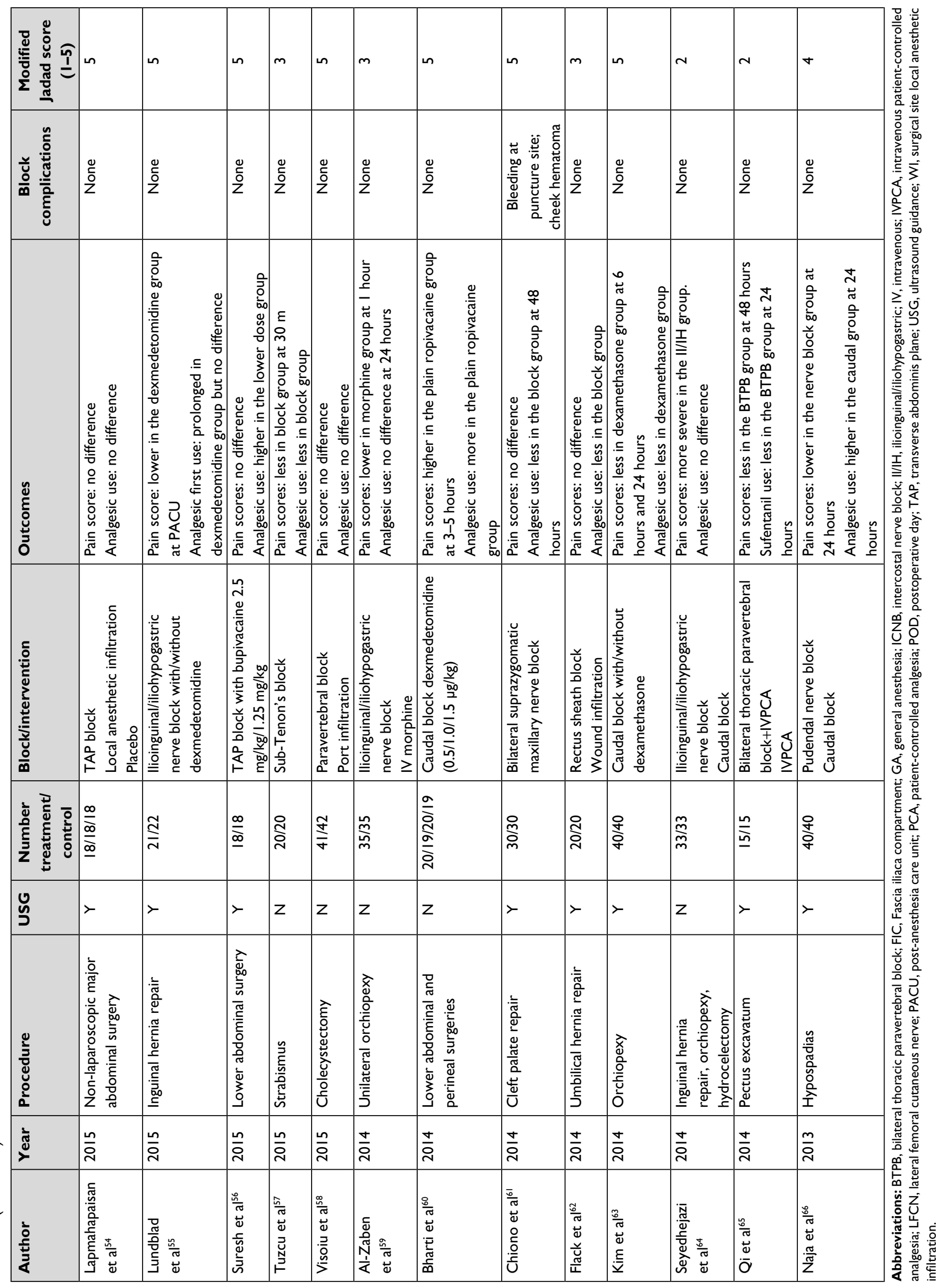


the intervention groups compared with those who received the EMLA cream alone. The addition of the ring block with the EMLA cream and oral sucrose provided more effective analgesia than the dorsal penile nerve block, EMLA cream, and oral sucrose. No adverse events were reported.

\section{Cleft palate repair}

Orofacial clefts, such as cleft palate, are a common congenital abnormality associated with severe postoperative pain. ${ }^{190,191}$ One study evaluated the efficacy of bilateral suprazygomatic maxillary nerve blocks on postoperative analgesia outcomes in pediatric patients undergoing cleft palate repair. ${ }^{61}$ The authors reported that bilateral suprazygomatic maxillary nerve blocks with ropivacaine lowered the overall morphine consumption compared with placebo after 48 hours following surgery. Interestingly, the postoperative pain scores were not different between ropivacaine and placebo groups. Two minor occurrences related to the nerve block were reported: one patient experienced bleeding at the puncture site while the other patient developed a cheek hematoma in the infrazygomatic area on postoperative day 1 . The hematoma resolved spontaneously by postoperative day 5 .

\section{Herniotomy}

One study investigated the use of a caudal block combined with intravenous dexamethasone on postoperative analgesia in pediatric patients scheduled to have unilateral herniotomy surgery. ${ }^{50}$ The children who received intravenous dexamethasone $(0.5 \mathrm{mg} / \mathrm{kg})$ following anesthesia induction reported less pain (Wong-Baker Face Scale) on postoperative days 1 and 2 compared with placebo. There was no pain reported in either group immediately following surgery in the postanesthesia care unit.

\section{Hypospadias}

Two studies investigated the use of regional anesthesia techniques for the pediatric population undergoing hypospadias surgery. ${ }^{42,66}$ Both studies compared pudendal nerve block with caudal block on postoperative analgesic outcomes 24 hours afterward. One study reported that patients who received an ultrasound-guided pudendal nerve block experienced less postoperative pain intensity compared with the caudal group. Moreover, all of the patients who received a caudal block requested additional analgesia medication compared with only $7.5 \%$ of the pudendal nerve block group. Taken together, it is not surprising that the patient satisfaction rate was lower in the caudal group. The other study evaluated the efficacy and analgesia duration of a nerve-stimulator guided pudendal nerve block compared with a caudal block. The postoperative pain scores at 24 hours were less in the pudendal nerve group compared with the caudal group. The total analgesic consumption at 24 hours following surgery was significantly reduced in the pudendal block group compared with the caudal group. Similar to the aforementioned study, the patient satisfaction was higher in the pudendal nerve block group.

\section{Inguinal hernia and groin}

Eight studies investigated regional anesthesia and its effect on postoperative analgesia in inguinal hernia and orchiopexy procedures. Three studies evaluated ultrasound-guided transversus abdominis plane (TAP) block on postoperative analgesia. ${ }^{33,38,41}$ One study reported a decrease in opioid consumption at 24 hours in the ultrasound-guided TAP block group compared with general anesthesia alone. The CHEOPS and the Behavioral Objective Pain Score (BOPS) were significantly lower in the TAP block group compared with the control. Another study compared ultrasound-guided TAP block to local anesthetic infiltration. At 24 hours after surgery, the patients who received the TAP block reported significantly lower pain scores and reduced total opioid consumption compared with the patients who received local anesthetic infiltration. Patient satisfaction was higher in the TAP block group. The third study evaluated the effect of adding dexmedetomidine to bupivacaine in pediatric patients scheduled to receive an ultrasound-guided TAP block as part of their postoperative multimodal regimen. The 24 hours total analgesic consumption was significantly higher in the bupivacaine group compared with those who received the combination of bupivacaine and dexmedetomidine.

Three studies assessed the use of ilioinguinal/iliohypogastric nerve blocks in children undergoing inguinal surgeries. ${ }^{45,55,64}$ One study reported postoperative pain (CHIPPS) in the post-anesthesia care unit (PACU) was significantly higher in the local anesthetic group compared with the ilioinguinal/iliohypogastric nerve block group. Another study compared intraoperative ultrasound-guided ilioinguinal/iliohypogastric nerve blocks with those who did not receive a block on postoperative analgesic outcomes. The BOPS was not different between groups at any of the four time points (PACU arrival, 30 minutes, 1 hour, and 4 hours). The next study investigated the addition of clonidine to either caudal blocks or ilioinguinal/iliohypogastric blocks on postoperative outcomes. Patients receiving the ilioinguinal/iliohypogastric blocks experienced more severe postoperative pain compared with the caudal group although 
it was not statistically significant. In addition, there was no difference in patients' postoperative analgesic consumption between groups.

Two studies evaluated the efficacy of caudal epidural anesthesia on postoperative analgesia in children undergoing orchiopexy and inguinal hernia repair. ${ }^{30,40}$ One study evaluated three different volumes of $0.25 \%$ levobupivacaine (low: $0.6 \mathrm{~mL} / \mathrm{kg}$; middle: $0.8 \mathrm{~mL} / \mathrm{kg}$; and high: $1.0 \mathrm{~mL} /$ $\mathrm{kg}$ ) and reported that the postoperative analgesic consumption at 6,12 , and 24 hours following surgery did not differ among groups. The postoperative pain was evaluated using the CHIPPS instrument which was not statistically different among groups at any time period. The last study evaluated the efficacy of adding clonidine to a caudal block to alleviate postoperative pain following orchiopexy or hernia repair procedures. No patients requested additional analgesia in either group in the first 6 hours following surgery. The postoperative pain scores (CHEOPS) at 12 and 24 hours were higher in patients who did not receive clonidine compared with those who received clonidine as part of their anesthetic block.

One study compared bilateral ultrasound-guided rectus sheath block with local anesthetic infiltration for laparoscopic percutaneous extraperitoneal closure during inguinal hernia repair in children. ${ }^{36}$ The pain score (Face, Legs, Activity, Cry, and Consolability [FLACC]) was higher on arrival to the PACU in the local anesthetic infiltration group compared with the rectus sheath block group. However, there was no difference in postoperative pain scores at 30 and 60 minutes between groups. No patients in either of the aforementioned studies experienced immediate or delayed complications.

\section{Lower abdominal procedures}

Six studies evaluated regional anesthesia and its effect on postoperative analgesia in lower abdominal procedures including herniorrhaphy, hydrocelectomy, and testicular detorsion.

Four studies examined the efficacy of transversus abdominis plane block for postoperative pain relief in pediatric population undergoing abdominal surgery. ${ }^{34,46,54,56}$ One study compared local infiltration with $0.25 \%$ bupivacaine, a control (no block group), and a surgeon-placed bilateral TAP block for non-laparoscopic abdominal procedures. The authors reported no difference in postoperative pain scores and no reduction in cumulative 24 hours opioid consumption among the groups. Suresh et al compared the analgesic efficacy of $1.25-2.5 \mathrm{mg} / \mathrm{kg}$ bupivacaine in children scheduled to receive a TAP block for postoperative pain relief. ${ }^{56}$ The pain scores in the PACU were not different between the study groups.
However, the 24 hours total analgesic consumption was higher in the low-dose group compared with the high-dose group. The authors concluded that the higher local anesthetic dose for TAP block in children does not provide benefits in the immediate postoperative recovery period but does seem to decrease the analgesic use 24 hours after surgery.

Another study compared ultrasound-guided TAP block with caudal block for postoperative pain relief after lower abdominal surgery. There was no difference in pain scores between groups in the first 6 hours following surgery. The children who received the caudal block reported a greater incidence of pain 6 hours following surgery than patients allocated to the TAP block group. No statistical difference was reported between groups regarding total opioid consumption.

Sahin et al compared three regional anesthesia techniques in children following elective unilateral lower abdominal surgery. ${ }^{34}$ The total analgesic consumption was higher in the ilioinguinal/iliohypogastric block compared with the TAP block and caudal block. The pain scores (CHEOPS) during the first 8 hours in the postoperative period were higher in the ilioinguinal/iliohypogastric group compared with the other two groups; however, the pain scores in the ilioinguinal/iliohypogastric group at 16 hours were higher compared with the caudal group. The authors concluded that caudal blocks and TAP blocks are more effective than ilioinguinal/ iliohypogastric nerve blocks in the early postoperative period.

One study compared the analgesic efficacy of caudal bupivacaine with two different caudal dexmedetomidine dosages ( 1 and $2 \mu \mathrm{g} / \mathrm{kg}$ ) for postoperative pain relief in pediatric children undergoing lower abdominal and perineal surgery. ${ }^{51}$ The time to first analgesic request was longer in children who were allocated to the dexmedetomidine groups compared with the plain bupivacaine group. The 24 hours postoperative analgesic consumption was higher in the plain bupivacaine group compared with either dexmedetomidine groups. However, patients who received dexmedetomidine experienced significantly higher postoperative sedation scores compared with plain bupivacaine group. Two patients who received the $1 \mu \mathrm{g} / \mathrm{kg}$ dexmedetomidine dose developed bradycardia and hypotension and one experienced urinary retention compared with none in the plain bupivacaine group.

A similar study compared caudal ropivacaine to the addition of three different dexmedetomidine dosages $(0.5$, 1 , and $1.5 \mu \mathrm{g} / \mathrm{kg}$ ) in caudal ropivacaine on postoperative analgesia in pediatric patients. ${ }^{60}$ The postoperative analgesia was significantly prolonged in all dexmedetomidine groups compared with the plain ropivacaine group. All children receiving plain ropivacaine required opioid analgesia in the 
first 6 hours following surgery compared with no opioid requests in all three dexmedetomidine groups. The plain ropivacaine group experienced higher pain scores (FLACC) between 3 and 5 hours following surgery compared with the dexmedetomidine groups. Patients who received $1.5 \mu \mathrm{g} / \mathrm{kg}$ dexmedetomidine experienced higher postoperative sedation scores and significantly prolonged sedation compared with the other groups.

\section{Microtia}

Microtia is a congenital deformity of the external ear that requires reconstructive surgery and rib cartilage harvesting. Children often complain of severe postoperative pain during the immediate postoperative period. Two studies examined regional anesthesia in children undergoing auricular reconstruction for postoperative pain relief., ${ }^{44,49}$ One study compared a single-shot intercostal nerve block containing ropivacaine to a 48 hours infusion of ropivacaine into the surgical site on postoperative analgesia outcomes. The supplemental analgesic use was significantly higher in the intercostal nerve block group compared with the surgical site infiltration group. The postoperative pain score (Face Scale; $0=$ none, $5=$ severe) was significantly lower in the surgical site infiltration group compared with the intercostal nerve block at 12 to 72 hours after surgery. No patients experienced symptoms of central nervous system or cardiovascular toxicity. The number of patients who experienced postoperative nausea and vomiting (PONV) was not different between groups.

The second study compared the combination of a singleshot intercostal nerve block followed by a catheter-based infusion of ropivacaine to intravenous analgesia on postoperative pain after rib harvesting for auricular reconstruction in children with microtia. The average pain scores (numerical pain rating score) of chest pain at rest and during coughing in the first 48 hours after the surgery was significantly lower in the intercostal nerve block plus infusion group compared with the intravenous analgesia (control) group. Ear pain was also significantly higher in the control group compared with the study group. Rescue medication during the first 48 hours following surgery was significantly less in the block plus infusion group compared with the intravenous analgesia group.

\section{Orchiopexy}

Two studies examined the use of regional anesthesia for postoperative pain relief in children undergoing orchiopexy. ${ }^{59,63}$ Orchiopexy is a commonly performed procedure in children with an undescended testicle or testes and is associated with moderate-to-severe postoperative pain lasting up to several days following surgery. ${ }^{192}$ One study compared the analgesic efficacy of caudal ropivacaine with and without dexamethasone $(0.1 \mathrm{mg} / \mathrm{kg})$ on postoperative pain and rescue analgesic consumption in children undergoing unilateral orchiopexy. The postoperative pain scores (numeric rating scale [NRS]) were significantly lower in the dexamethasone group compared with the plain ropivacaine group up to 48 hours following surgery. At 48 hours after surgery, there was no difference in the pain scores between groups. Consumption of oral analgesics at 48 hours after surgery was less in the dexamethasone group (28.9\%) compared with the plain ropivacaine group (54.1\%).

The other study compared ilioinguinal/iliohypogastric nerve block to intravenous morphine in pediatric patients undergoing unilateral orchiopexy surgery. The postoperative pain scores (NRS) were significantly lower in the morphine group compared with the block group in the first hour after surgery. After 60 minutes in the PACU, there was no difference in pain scores between groups. The 24 hours postoperative analgesic consumption was not different between groups. Patients allocated to the morphine group experienced more vomiting and itching compared with the nerve block group.

\section{Orthopedic procedures}

Four studies investigated the use of regional anesthesia for postoperative analgesia outcomes in children scheduled to undergo lower extremity orthopedic procedures. ${ }^{31,32,37,43}$ As a component of multimodal anesthesia, regional anesthesia techniques are increasing in popularity for surgical procedures especially in orthopedic surgery. ${ }^{193-195}$ One study compared ultrasound-guided femoral nerve block together with the obturator nerve to a no-nerve block group. The postoperative pain score (Wong-Baker FACE Scale) was significantly lower in the children who received a nerve block compared with those who did not receive a nerve block. In addition, the postoperative analgesic consumption was also significantly less in the block group.

The second study compared the use of a bupivacaine caudal block with and without dexamethasone and intravenous dexamethasone on postoperative pain in pediatric patients undergoing lower limb orthopedic surgery. ${ }^{37}$ In the first 8 hours and the 12 to 24 hours postoperative period, the postoperative pain scores were higher in the patients who received the caudal epidural with plain bupivacaine compared with those allocated to either dexamethasone groups (caudal or intravenous). There was no difference in pain scores among all three groups at the 12 hours postoperative period. The number of analgesic doses requested was significantly lower in the dexamethasone groups compared with the caudal block 
with plain bupivacaine. Moreover, no difference was reported between the plain bupivacaine caudal with intravenous dexamethasone group and the caudal dexamethasone group.

The third study compared the efficacy of epidural adjuvants, dexmedetomidine, and fentanyl to local anesthetics in pediatric orthopedic surgery. ${ }^{32}$ The median postoperative pain score (revised scale FLACC) ${ }^{196}$ was not different among groups at PACU arrival, 12, 24, and 48 hours after surgery. At 6 hours following surgery, the dexmedetomidine group reported significantly lower pain scores compared with the fentanyl group. Rescue analgesic use was not different between groups throughout the 48 hours follow-up period.

Another study evaluated the effects of preoperative ultrasound-guided popliteal block on analgesic outcomes in children with cerebral palsy undergoing lower limb surgery. ${ }^{31}$ The total paracetamol consumption was significantly lower in the popliteal nerve block group compared with the non-block group. The postoperative pain scores (Wong-Baker FACE Scale) were higher in the control group compared with the nerve block group at 10 minutes, 20 minutes, and up to 12 hours postoperatively. There was no difference in pain scores between groups at 24 hours after surgery.

The last study in the group compared ultrasound-guided infraclavicular brachial plexus blocks with two different local anesthetic dosages in children undergoing upper extremity orthopedic surgery. ${ }^{27}$ The authors detected no statistical difference in postoperative pain scores (Wong-Baker FACE Scale) between local anesthetic volumes of $0.5 \%$ bupivacaine $(0.25$ and $0.50 \mathrm{~mL} / \mathrm{kg})$ during the first 24 hours following surgery. No block complications such as pneumothorax or hematoma were reported in either group.

\section{Pectus excavatum}

Pectus excavatum is the most common congenital chest wall deformity in children with an incidence of one in $400 .{ }^{197}$ The Nuss procedure is a surgical procedure in which a substernal bar is implanted into the anterior chest wall to help stabilize its shape. The procedure is associated with moderate postoperative pain which may affect postoperative rehabilitation and lead to an increased length of hospitalization. ${ }^{198,199}$ Two studies investigated the effectiveness of regional anesthesia in providing postoperative pain in children undergoing the Nuss procedure. ${ }^{29,65}$ One study compared ultrasound-guided bilateral intercostal nerve blocks with intravenous analgesia for postoperative analgesia. The postoperative pain scores (Faces Pain Scale-Revised, FPS-R) in the first 6 hours were significantly decreased in the nerve block group compared with the control group. The 24 hours opioid consumption was significantly less in the nerve block group compared with the control group.

The other study examined the use of ultrasoundguided bilateral thoracic PVBs and intravenous PCA for postoperative pain. The postoperative pain scores (FLACC; visual analog scale) were significantly reduced in the nerve block group compared with the control group in the first 48 hours following surgery. The 24 hours cumulative opioid consumption was significantly higher in the control group compared with that in the nerve block group. No immediate nerve block complications were reported by the authors in either study.

\section{Umbilical hernia}

Two studies investigated the effectiveness of regional anesthesia on postoperative pain for umbilical hernia repair in children. Flack et al compared the use of ultrasound-guided rectus sheath blocks with surgical site infiltration on postoperative opioid consumption and reported that children allocated to the block group consumed significantly less opioids than those in the surgical site infiltration group. ${ }^{62}$ However, there was no difference in the average maximum pain scores between groups.

The second study compared the use of preoperative ultrasound-guided rectus sheath blocks with surgeon-placed rectus sheath blocks for postoperative pain relief. ${ }^{28}$ The mean postoperative pain scores (Wong-Baker FACE Scale) and analgesia consumption in the post-anesthesia care unit were similar between groups.

\section{Renal transplant}

A single study evaluated the effectiveness of a caudal epidural block with and without intravenous fentanyl and paracetamol for postoperative pain relief in children undergoing renal transplantation. ${ }^{48}$ Postoperative pain management after renal transplantation poses a challenge due to the limited kidney function and possible respiratory depression from systemic opioids. ${ }^{200-202}$ The placement of catheters to the thoracic level through the caudal route has been described in many studies and is thought to be safer than direct catheter placement at the lumbar or thoracic levels in children receiving general anesthesia. ${ }^{203,204}$ Soaida et al reported postoperative pain scores that were statistically higher at 6,12 , and 18 hours in the intravenous fentanyl group compared with those who received the caudal epidural block. ${ }^{48}$ Over half of the patients in the control group compared with none in the caudal group received rescue analgesia upon arriving to the post-anesthesia care unit. There were two cases in which 
threading the epidural catheter to the thoracic region failed and were excluded from the study.

\section{Strabismus}

One study examined regional anesthesia on postoperative pain in pediatric ocular procedures. Strabismus surgery is a common pediatric ocular operation that causes several unpleasant side effects throughout the perioperative period. The most concerning issue is the occurrence of the oculocardiac reflex. It is associated with increased PONV due to the disturbance of the extraocular muscles during surgery. ${ }^{205}$ Tuzcu et al compared the effectiveness of sub-Tenon's block on postoperative analgesia in children having strabismus surgery. ${ }^{57}$ Patient who received the block reported lower postoperative pain scores (NRS $0-4$; $0=$ no pain, $4=$ very severe pain) 30 minutes following the procedure compared with those who did not receive the block. In addition, postoperative analgesic use was less in the block group compared with the control group.

\section{Burn reconstructive surgery}

One study investigated the use of ultrasound-guided regional anesthesia for postoperative pain control in pediatric burn patients undergoing reconstructive surgery. Burn patients often undergo multiple reconstructive surgeries to regain body function and esthetics. ${ }^{206}$ Postoperative pain following skin grafting has been challenging and is a main reason for patients to decline reconstructive procedures. Shank et al compared surgical site infiltration $(0.25 \%$ bupivacaine), ultrasound-guided single-shot lateral femoral cutaneous nerve block, and ultrasound-guided continuous infusion fascia-iliaca compartment block on postoperative pain in children undergoing reconstructive skin grafting. ${ }^{47}$ The authors reported that patients who received regional anesthesia via single-shot lateral femoral cutaneous nerve block (LFCNB) or catheter infusion fascia iliaca compartment block (FICB) experienced less pain than those in the surgical site infiltration group. The patients in the LFCNB group reported significantly less postoperative pain upon arrival to the post-anesthesia care unit until discharge to the floor compared with the FICB group or the control group. However, patients in the FICB group reported significantly lower pain scores on postoperative days 1 and 2 compared with LFCNB and the control group. There was no difference in opioid consumption among all three groups.

\section{Discussion}

The current investigation demonstrates that the number of clinical trials supporting the use of regional anesthesia for the management of postoperative pain has increased in children undergoing surgery. Notably, of the 2,408 patients included in the review, no significant complication attributed to the regional anesthesia techniques such as systemic toxicity or neurological sequelae was reported. The majority of the regional anesthesia techniques were performed using ultrasound guidance, which may be a contributing factor in the observed increased rate of publication of clinical trials in this area. The ability to provide site-specific analgesia while reducing opioid consumption results in targeted pain relief with fewer side effects. Although there has been an increase in the use of regional anesthesia in the pediatric literature demonstrating improvement of postoperative outcomes, our review calls for further examination of the effect of regional anesthesia techniques on postoperative outcomes in pediatric patients.

The strongest evidence to support the use of regional anesthesia for postoperative pain management in children was demonstrated by studies of intercostal nerve blocks (three studies) for reconstructive ear surgery and chest wall deformity. A decrease in postoperative discomfort and analgesic consumption was more pronounced in patients receiving intercostal nerve blocks compared with local anesthetic infusion or infiltration of the surgical site.

Pudendal nerve block is commonly used in adults undergoing obstetric and anorectal procedures. The use of a pudendal nerve block (two studies) for postoperative pain management in pediatric hypospadias surgery provided superior pain relief and reduced 24 hours analgesic consumption compared with caudal blocks, resulting in fewer side effects and improvement in sleep patterns.

Bilateral suprazygomatic maxillary nerve blocks (one study) provided good pain relief by reducing the total opioid consumption 48 hours following cleft palate repair compared with placebo and show promise as an alternative to intravenous opioids. Other regional anesthesia techniques, such as rectus sheath blocks for umbilical hernia surgery, reduced opioid consumption compared with local anesthetic infiltration of the surgical site.

In contrast, several studies have shown a marginal benefit of regional anesthesia in postoperative pain management in children. Similar to our previous study, ${ }^{21}$ ilioinguinal/iliohypogastric nerve blocks for inguinal hernia repair demonstrate mixed results.

Abu Elyazed et al reported a decrease in total opioid consumption at 24 hours following surgery in patients receiving an ultrasound-guided TAP block compared with general anesthesia alone. ${ }^{38}$ This finding is similar to previous 
reports that demonstrated that local anesthetics lowered postoperative analgesic requirements compared with general anesthesia. ${ }^{207-209}$ Compared with TAP block or caudal block, ilioinguinal/iliohypogastric nerve blocks did not provide substantial pain relief or reduce opioid consumption in the early postoperative period. ${ }^{34}$ However, the use of ilioinguinal/ iliohypogastric nerve blocks for unilateral orchiopexy procedures provides short-term pain relief, and patients experience fewer side effects than with intravenous analgesics. ${ }^{59}$

The use of PVBs for postoperative pain relief following cholecystectomy in pediatric patients demonstrated inconclusive results when compared with local anesthetic infiltration at laparoscopic port sites. Similar inconclusive reports on the application of thoracic PVBs and neuraxial anesthesia for cholecystectomy have been published in adult patients. ${ }^{210-212}$ However, patients who received bilateral paravertebral nerve blocks following reconstructive chest wall repair experienced excellent pain relief in the first 48 hours following the procedure.

Caudal epidural blocks are one of the most commonly performed techniques in pediatric regional anesthesia with success rates of above $95 \% .{ }^{213}$ In the present review, we found that almost half of the studies that contained a caudal block arm used ultrasound guidance during catheter placement which is higher than our previous report. Caudal blocks together with dexamethasone provided improved postoperative pain relief (greater than 6 hours), particularly in children undergoing orchiopexy and lower extremity orthopedic surgery. This finding is similar to the report by Hong et al which reported a single dose of intravenous dexamethasone combined with a caudal block prolonged postoperative pain relief in pediatric orchiopexy. ${ }^{214}$

In contrast, all children recovering from hypospadias surgery who received a caudal block requested additional analgesics, suggesting inadequate pain relief. Further investigations involving the safety of regional neuraxial techniques with adjuvants in children are warranted.

Use of additives to local anesthetics for prolongation of the duration of analgesia is common, as this may decrease the total amount of local anesthetic that is necessary. ${ }^{215-217}$ Clonidine has been shown to improve postoperative pain control. $^{218,219}$ Several trials evaluated the use of adjuvants, such as clonidine and dexmedetomidine, together with local anesthetics and reported that patients requested less supplemental medication due to the enhanced analgesia. ${ }^{51,55}$ However, patients who received dexmedetomidine experienced excessive sedation, and two patients experienced side effects, which suggests that appropriate dosing of dexmedetomidine in children deserves further investigation. ${ }^{220,221}$ The use of adjuvants to local anesthetics in the pediatric population is limited and further studies evaluating its enhanced analgesic effect and safety profile in children are warranted.

\section{Limitations}

Our review must be interpreted within the context of the study's limitations. Comparisons in pragmatic trials were heterogeneous (different drugs, adjuvants, or both) and the number of trials for the same surgical procedure was small. We did not carry out a quantitative analysis and limited our review to a qualitative evaluation. We could not assess the existence of publication bias, and it is plausible that negative trials investigating analgesic outcomes were never published. In addition, we did not evaluate if variations of block technique affected pain outcomes.

\section{Conclusion}

We performed a systemic review of randomized controlled trials published from 2013 to 2017 in order to assess the effectiveness of regional anesthesia procedures on postoperative outcomes in children after pediatric surgery. Although there are challenges with conducting randomized controlled trials in children, the quantity and quality of the number of pediatric studies published on the topic of regional anesthesia techniques have increased. Still, further trials are needed to improve our knowledge of the benefits and risks of regional anesthesia techniques associated with specific pediatric procedures.

\section{Disclosure}

The authors report no conflicts of interest in this work.

\section{References}

1. Gan TJ. Poorly controlled postoperative pain: prevalence, consequences, and prevention. J Pain Res. 2017;10:2287-2298.

2. Sinatra R. Causes and consequences of inadequate management of acute pain. Pain Med. 2010;11(12):1859-1871.

3. Krane EJ, Weisman SJ, Walco GA. The National Opioid Epidemic and the Risk of Outpatient Opioids in Children. Pediatrics. 2018;142(2):e20181623.

4. Liu C, Ulualp SO. Outcomes of an Alternating Ibuprofen and Acetaminophen Regimen for Pain Relief After Tonsillectomy in Children. Ann Otol Rhinol Laryngol. 2015;124(10):777-781.

5. McNicol ED, Rowe E, Cooper TE. Ketorolac for postoperative pain in children. Cochrane Database Syst Rev. 2018;7:CD012294.

6. Harbaugh CM, Lee JS, Hu HM, et al. Persistent opioid use among pediatric patients after surgery. Pediatrics. 2018;141(1):e20172439.

7. Shah RD, Suresh S. Acute pain management in the pediatric ambulatory setting: How do we optimize the child's postoperative experience? J Clin Anesth. 2017;40:103-104.

8. van Cleve WC, Grigg EB. Variability in opioid prescribing for children undergoing ambulatory surgery in the United States. J Clin Anesth. 2017;41:16-20.

9. Waljee JF, Zhong L, Hou H, Sears E, Brummett C, Chung KC. The use of opioid analgesics following common upper extremity surgical procedures: a national, population-based study. Plast Reconstr Surg. 2016;137(2):355e-364e. 
10. Verghese ST, Hannallah RS. Acute pain management in children. J Pain Res. 2010;3:105-123.

11. Cai Y, Lopata L, Roh A, et al. Factors influencing postoperative pain following discharge in pediatric ambulatory surgery patients. $J$ Clin Anesth. 2017;39:100-104.

12. Joshi G, Gandhi K, Shah N, Gadsden J, Corman SL. Peripheral nerve blocks in the management of postoperative pain: challenges and opportunities. J Clin Anesth. 2016;35:524-529.

13. Shah RD, Suresh S. Applications of regional anaesthesia in paediatrics. Br J Anaesth. 2013;111(Suppl 1):i114-i124.

14. Jöhr M. Regional anaesthesia in neonates, infants and children: an educational review. Eur J Anaesthesiol. 2015;32(5):289-297.

15. Coraci D, Santilli V, Giovannini S, Padua L. The important use of ultrasound on a child with chronic pain. J Clin Anesth. 2017;38:105-106.

16. Samol NB, Furstein JS, Moore DL. Regional anesthesia and pain management for the pediatric patient. Int Anesthesiol Clin. 2012;50(4):83-95.

17. Krause M, Khatibi B, Sztain JF, Rahman P, Shapiro AB, Sandhu NS. Ultrasound-guided airway blocks using a curvilinear probe. J Clin Anesth. 2016;33:408-412.

18. Stein AL, Baumgard D, del Rio I, Tutiven JL. Updates in Pediatric Regional Anesthesia and Its Role in the Treatment of Acute Pain in the Ambulatory Setting. Curr Pain Headache Rep. 2017;21(2):11.

19. Polaner DM, Taenzer AH, Walker BJ, et al. Pediatric Regional Anesthesia Network (PRAN): a multi-institutional study of the use and incidence of complications of pediatric regional anesthesia. Anesth Analg. 2012;115(6):1353-1364.

20. Ecoffey C, Lacroix F, Giaufré E, Orliaguet G, Courrèges P; Association des Anesthésistes Réanimateurs Pédiatriques d'Expression Française (ADARPEF). Epidemiology and morbidity of regional anesthesia in children: a follow-up one-year prospective survey of the FrenchLanguage Society of Paediatric Anaesthesiologists (ADARPEF). Paediatr Anaesth. 2010;20(12):1061-1069.

21. Suresh S, Schaldenbrand K, Wallis B, de Oliveira GS. Regional anaesthesia to improve pain outcomes in paediatric surgical patients: a qualitative systematic review of randomized controlled trials. $\mathrm{Br} J$ Anaesth. 2014;113(3):375-390.

22. Liberati A, Altman DG, Tetzlaff J, et al. The PRISMA statement for reporting systematic reviews and meta-analyses of studies that evaluate health care interventions: explanation and elaboration. J Clin Epidemiol. 2009;62(10):e1-e34.

23. Jadad AR, Moore RA, Carroll D, et al. Assessing the quality of reports of randomized clinical trials: is blinding necessary? Control Clin Trials. 1996;17(1):1-12.

24. De Oliveira GS, Castro-Alves LJ, Ahmad S, Kendall MC, McCarthy RJ. Dexamethasone to prevent postoperative nausea and vomiting: an updated meta-analysis of randomized controlled trials. Anesth Analg. 2013;116(1):58-74.

25. de Oliveira GS, Chang R, Kendall MC, Fitzgerald PC, Mccarthy RJ. Publication bias in the anesthesiology literature. Anesth Analg. 2012;114(5):1042-1048.

26. de Oliveira GS, Castro-Alves LJ, Chang R, Yaghmour E, Mccarthy RJ. Systemic metoclopramide to prevent postoperative nausea and vomiting: a meta-analysis without Fujii's studies. Br J Anaesth. 2012;109(5):688-697.

27. Ince I, Aksoy M, Dostbil A, Tuncer K. Can we use lower volume of local anesthetic for infraclavicular brachial plexus nerve block under ultrasound guidance in children? J Clin Anesth. 2017;41:132-136.

28. Litz CN, Farach SM, Fernandez AM, et al. Percutaneous ultrasound-guided vs. intraoperative rectus sheath block for pediatric umbilical hernia repair: A randomized clinical trial. J Pediatr Surg. 2017;52(6):901-906.

29. Luo M, Liu X, Ning L, Sun Y, Cai Y, Shen S. Comparison of Ultrasonography-guided Bilateral Intercostal Nerve Blocks and Conventional Patient-controlled Intravenous Analgesia for Pain Control After the Nuss Procedure in Children: A Prospective Randomized Study. Clin J Pain. 2017;33(7):604-610.
30. Marjanovic V, Budic I, Stevic M, Simic D. A Comparison of Three Different Volumes of Levobupivacaine for Caudal Block in Children Undergoing Orchidopexy and Inguinal Hernia Repair. Med Princ Pract. 2017;26(4):331-336.

31. Ozkan D, Gonen E, Akkaya T, Bakir M. Popliteal block for lower limb surgery in children with cerebral palsy: effect on sevoflurane consumption and postoperative pain (a randomized, double-blinded, controlled trial). J Anesth. 2017;31(3):358-364.

32. Park SJ, Shin S, Kim SH, et al. Comparison of Dexmedetomidine and Fentanyl as an Adjuvant to Ropivacaine for Postoperative Epidural Analgesia in Pediatric Orthopedic Surgery. Yonsei Med J. 2017;58(3):650-657.

33. Raof RA, El Metainy SA, Alia DA, Wahab MA. Dexmedetomidine decreases the required amount of bupivacaine for ultrasound-guided transversus abdominis plane block in pediatrics patients: a randomized study. J Clin Anesth. 2017;37:55-60.

34. Sahin L, Soydinc MH, Sen E, Cavus O, Sahin M. Comparison of 3 different regional block techniques in pediatric patients. A prospective randomized single-blinded study. Saudi Med J. 2017;38(9): 952-959.

35. Sharara-Chami R, Lakissian Z, Charafeddine L, Milad N, El-Hout Y. Combination Analgesia for Neonatal Circumcision: A Randomized Controlled Trial. Pediatrics. 2017;140(6):e20171935.

36. Uchinami Y, Sakuraya F, Tanaka N, et al. Comparison of the analgesic efficacy of ultrasound-guided rectus sheath block and local anesthetic infiltration for laparoscopic percutaneous extraperitoneal closure in children. Paediatr Anaesth. 2017;27(5):516-523.

37. Abd-Elshafy SK, Yacoup AM, Abdalla EE, El-Melegy TT, AbdElsalam KA. A New Look on Adding Dexamethasone as an Adjuvant to Caudal Bupivacaine; Efficacy on Postoperative Pain and Vomiting in Pediatric Patients. Pain Physician. 2016;19(6):E841-E852.

38. Abu Elyazed MM, Mostafa SF, Abdullah MA, Eid GM. The effect of ultrasound-guided transversus abdominis plane (TAP) block on postoperative analgesia and neuroendocrine stress response in pediatric patients undergoing elective open inguinal hernia repair. Paediatr Anaesth. 2016;26(12):1165-1171.

39. Anouar J, Mohamed S, Sofiene A, Jawhar Z, Sahar E, Kamel K. The analgesic effect of clonidine as an adjuvant in dorsal penile nerve block. Pan Afr Med J. 2016;23:213.

40. Jarraya A, Elleuch S, Zouari J, Smaoui M, Laabidi S, Kolsi K. Postoperative analgesia in children when using clonidine in addition to fentanyl with bupivacaine given caudally. Pan Afr Med J. 2016;24:182.

41. Kendigelen P, Tutuncu AC, Erbabacan E, et al. Ultrasound-assisted transversus abdominis plane block vs wound infiltration in pediatric patient with inguinal hernia: randomized controlled trial. JClin Anesth. 2016;30:9-14.

42. Kendigelen P, Tutuncu AC, Emre S, Altindas F, Kaya G. Pudendal Versus Caudal Block in Children Undergoing Hypospadias Surgery: A Randomized Controlled Trial. Reg Anesth Pain Med. 2016;41(5):610-615.

43. Marinkovic D, Simin JM, Draskovic B, Kvrgic IM, Pandurov M. Efficiency of ultrasound guided lower limb peripheral nerve blocks in perioperative pain management for knee arthroscopy in children. A randomized study. Med Pregl. 2016;69(1-2):5-10.

44. Niiyama Y, Yotsuyanagi T, Yamakage M. Continuous wound infiltration with $0.2 \%$ ropivacaine versus a single intercostal nerve block with $0.75 \%$ ropivacaine for postoperative pain management after reconstructive surgery for microtia. J Plast Recon Aesth Surg. 2016;69(10):1445-1449.

45. Ohashi N, Denda S, Furutani K, et al. Ultrasound-guided ilioinguinal/iliohypogastric block did not reduce emergence delirium after ambulatory pediatric inguinal hernia repair: a prospective randomized double-blind study. Surg Today. 2016;46(8):963-969.

46. Sethi N, Pant D, Dutta A, Koul A, Sood J, Chugh PT. Comparison of caudal epidural block and ultrasonography-guided transversus abdominis plane block for pain relief in children undergoing lower abdominal surgery. J Clin Anesth. 2016;33:322-329. 
47. Shank ES, Martyn JA, Donelan MB, Perrone A, Firth PG, Driscoll DN. Ultrasound-Guided Regional Anesthesia for Pediatric Burn Reconstructive Surgery: A Prospective Study. J Burn Care Res. 2016;37(3):e213-e217.

48. Soaida SM, Elsheemy MS, Shouman AM, et al. Caudal extradural catheterization in pediatric renal transplant and its effect on perioperative hemodynamics and pain scoring: a prospective randomized study. J Anesth. 2016;30(1):47-54.

49. Woo KJ, Kang BY, Min JJ, Park JW, Kim A, Oh KS. Postoperative pain control by preventive intercostal nerve block under direct vision followed by catheter-based infusion of local analgesics in rib cartilage harvest for auricular reconstruction in children with microtia: A randomized controlled trial. J Plast Reconstr Aesthet Surg. 2016;69(9):1203-1210.

50. Arbi MSA, Izagam A, Kamaruzaman E, Zainuddin K, Ismail H, Manap NA. Intravenous dexamethasone in combination with caudal block prolongs postoperative analgesia in pediatric daycare surgery. Middle East J Anaesthesiol. 2015;23(2):177-183.

51. Al-Zaben KR, Qudaisat IY, Abu-Halaweh SA, et al. Comparison of caudal bupivacaine alone with bupivacaine plus two doses of dexmedetomidine for postoperative analgesia in pediatric patients undergoing infra-umbilical surgery: a randomized controlled double-blinded study. Paediatr Anaesth. 2015;25(9):883-890.

52. Bryskin RB, Londergan B, Wheatley R, et al. Transversus Abdominis Plane Block Versus Caudal Epidural for Lower Abdominal Surgery in Children: A Double-Blinded Randomized Controlled Trial. Anesth Analg. 2015;121(2):471-478.

53. Hamill JK, Rahiri JL, Liley A, Hill AG. Rectus sheath and transversus abdominis plane blocks in children: a systematic review and meta-analysis of randomized trials. Paediatr Anaesth. 2016;26(4): 363-371.

54. Lapmahapaisan S, Tantemsapya N, Aroonpruksakul N, Maisat W, Suraseranivongse $\mathrm{S}$. Efficacy of surgical transversus abdominis plane block for postoperative pain relief following abdominal surgery in pediatric patients. Paediatr Anaesth. 2015;25(6):614-620.

55. Lundblad M, Marhofer D, Eksborg S, Lönnqvist PA. Dexmedetomidine as adjunct to ilioinguinal/iliohypogastric nerve blocks for pediatric inguinal hernia repair: an exploratory randomized controlled trial. Paediatr Anaesth. 2015;25(9):897-905.

56. Suresh S, Taylor LJ, de Oliveira GS. Dose effect of local anesthetics on analgesic outcomes for the transversus abdominis plane (TAP) block in children: a randomized, double-blinded, clinical trial. Paediatr Anaesth. 2015;25(5):506-510.

57. Tuzcu K, Coskun M, Tuzcu EA, et al. Effectiveness of sub-Tenon's block in pediatric strabismus surgery. Rev Bras Anestesiol. 2015;65(5):349-352.

58. Visoiu M, Cassara A, Yang CI. Bilateral Paravertebral Blockade (T710) Versus Incisional Local Anesthetic Administration for Pediatric Laparoscopic Cholecystectomy: A Prospective, Randomized Clinical Study. Anesth Analg. 2015;120(5):1106-1113.

59. Al-Zaben KR, Qudaisat IY, Abu-Halaweh SA, et al. Comparison of ilioinguinal/iliohypogastric nerve blocks and intravenous morphine for control of post-orchidopexy pain in pediatric ambulatory surgery. Middle East J Anaesthesiol. 2014;22(4):393-398.

60. Bharti N, Praveen R, Bala I. A dose-response study of caudal dexmedetomidine with ropivacaine in pediatric day care patients undergoing lower abdominal and perineal surgeries: a randomized controlled trial. Paediatr Anaesth. 2014;24(11):1158-1163.

61. Chiono J, Raux O, Bringuier S, et al. Bilateral suprazygomatic maxillary nerve block for cleft palate repair in children: a prospective, randomized, double-blind study versus placebo. Anesthesiology. 2014;120(6):1362-1369.

62. Flack SH, Martin LD, Walker BJ, et al. Ultrasound-guided rectus sheath block or wound infiltration in children: a randomized blinded study of analgesia and bupivacaine absorption. Paediatr Anaesth. 2014;24(9):968-973.
63. Kim EM, Lee JR, Koo BN, Im YJ, Oh HJ, Lee JH. Analgesic efficacy of caudal dexamethasone combined with ropivacaine in children undergoing orchiopexy. Br J Anaesth. 2014;112(5):885-891.

64. Seyedhejazi M, Sheikhzadeh D, Adrang Z, Rashed FK. Comparing the analgesic effect of caudal and ilioinguinal iliohypogastric nerve blockade using bupivacaine-clonidine in inguinal surgeries in children 2-7 years old. Afr J Paediatr Surg. 2014;11(2):166-169.

65. Qi J, du B, Gurnaney H, Lu P, Zuo Y. A prospective randomized observer-blinded study to assess postoperative analgesia provided by an ultrasound-guided bilateral thoracic paravertebral block for children undergoing the Nuss procedure. Reg Anesth Pain Med. 2014;39(3):208-213.

66. Naja ZM, Ziade FM, Kamel R, El-Kayali S, Daoud N, El-Rajab MA. The effectiveness of pudendal nerve block versus caudal block anesthesia for hypospadias in children. Anesth Analg. 2013;117(6):1401-1407.

67. Kim HJ, Shin WJ, Park S, Ahn HS, Oh JH. The sedative effects of the intranasal administration of dexmedetomidine in children undergoing surgeries compared to other sedation methods: A systematic review and meta-analysis. J Clin Anesth. 2017;38:33-39.

68. Lam DK, Corry GN, Tsui BC. Evidence for the Use of Ultrasound Imaging in Pediatric Regional Anesthesia: A Systematic Review. Reg Anesth Pain Med. 2016;41(2):229-241.

69. Black KJ, Bevan CA, Murphy NG, Howard JJ. Nerve blocks for initial pain management of femoral fractures in children. Cochrane Database Syst Rev. 2013;12(12):CD009587.

70. Lee JH, Oh HW, Song IK, Kim JT, Kim CS, Kim HS. Determination of insertion depth of flexible laryngeal mask airway in pediatric population-A prospective observational study. J Clin Anesth. 2017;36:76-79.

71. Tirotta CF, Lagueruela RG, Madril D, et al. Non-invasive cardiac output monitor validation study in pediatric cardiac surgery patients. J Clin Anesth. 2017;38:129-132.

72. Pour PS, Ameri GF, Kazemi M, Jahani Y. Comparison of Effects of Local Anesthesia and Two-Point Acupressure on the Severity of Venipuncture Pain Among Hospitalized 6-12-Year-Old Children. $J$ Acupunct Meridian Stud. 2017;10(3):187-192.

73. Lu J, Chen G, Zhou H, Zhou Q, Zhu Z, Wu C. Effect of parecoxib sodium pretreatment combined with dexmedetomidine on early postoperative cognitive dysfunction in elderly patients after shoulder arthroscopy: A randomized double blinded controlled trial. J Clin Anesth. 2017;41:30-34.

74. Hong B, Lim CS, Kim YH, et al. Comparison of topical ropivacaine with and without ketamine on post-surgical pain in children undergoing tonsillectomy: a randomized controlled double-blind study. $J$ Anesth. 2017;31(4):559-564.

75. Sayed JA, F Riad MA, M Ali MO. Comparison of dexamethasone or intravenous fluids or combination of both on postoperative nausea, vomiting and pain in pediatric strabismus surgery. $J$ Clin Anesth. 2016;34:136-142.

76. Templeton TW, Hoke LK, Templeton LB, Ririe DG, Rose DM, Bryan YF. A comparison of 3 ventilation strategies in children younger than 1 year using a Proseal laryngeal mask airway: a randomized controlled trial. J Clin Anesth. 2016;35:502-508.

77. Gupta NK, Upadhyay A, Dwivedi AK, Agarwal A, Jaiswal V, Singh A. Randomized controlled trial of topical EMLA and vapocoolant spray for reducing pain during wDPT vaccination. World J Pediatr. 2017;13(3):236-241.

78. Adler AC, Schwartz ER, Waters JM, Stricker PA. Anesthetizing a child for a large compressive mediastinal mass with distraction techniques and music therapies as the sole agents. J Clin Anesth. 2016;35:392-397.

79. Min CB, Kain ZN, Stevenson RS, Jenkins B, Fortier MA. A randomized trial examining preoperative sedative medication and postoperative sleep in children. $J$ Clin Anesth. 2016;30:15-20.

80. Jarraya A, Elleuch S, Zouari J, Smaoui M, Laabidi S, Kolsi K. Postoperative analgesia in children when using clonidine in addition to fentanyl with bupivacaine given caudally. Pan Afr Med J. 2016;24:182. 
81. Khalil I, Itani SE, Naja Z, et al. Nerve stimulator-guided pudendal nerve block vs general anesthesia for postoperative pain management after anterior and posterior vaginal wall repair: a prospective randomized trial. J Clin Anesth. 2016;34:668-675.

82. Ozturk T, Acıkel A, Yılmaz O, Topçu I, Çevıkkalp E, Yuksel H. Effects of low-dose propofol vs ketamine on emergence cough in children undergoing flexible bronchoscopy with sevoflurane-remifentanil anesthesia: a randomized, double-blind, placebo-controlled trial. $J$ Clin Anesth. 2016;35:90-95.

83. Kumar KR, Kumar H, Baidya DK, Arora MK. Successful use of spinal anesthesia for inguinal hernia repair in a child with Hunter syndrome with difficult airway. J Clin Anesth. 2016;30:99-100.

84. Tian X, Yang P, Su T, et al. Intraperitoneal ropivacaine and early postoperative pain and postsurgical outcomes after laparoscopic herniorrhaphy in toddlers: a randomized clinical trial. Paediatr Anaesth. 2016;26(9):891-898.

85. Dobie KH, ShiY, Shotwell MS, Sandberg WS. New technique targeting the $\mathrm{C} 5$ nerve root proximal to the traditional interscalene sonoanatomical approach is analgesic for outpatient arthroscopic shoulder surgery. J Clin Anesth. 2016;34:79-84.

86. Senturk MB, Guraslan H, Babaoğlu B, Yaşar L, Polat M. The Effect of Intrauterine Lidocaine and Rectal Indomethacin on Pain during Office Vaginoscopic Hysteroscopy: Randomized Double-Blind Controlled Study. Gynecol Obstet Invest. 2016;81(3):280-284.

87. Ueshima H, Myint KZ, Otake H. Detection of large perforating artery by ultrasound prescan before obturator nerve block. J Clin Anesth. 2016;29:14

88. Kumar N, Sardana R, Kaur R, Jain A. Intraoperative mandibular nerve block with peripheral nerve stimulator for temporomandibular joint ankylosis. J Clin Anesth. 2016;35:207-209.

89. Perotti L, Cusato M, Ingelmo P, et al. A Comparison of Differences Between the Systemic Pharmacokinetics of Levobupivacaine and Ropivacaine During Continuous Epidural Infusion: A Prospective, Randomized, Multicenter, Double-Blind Controlled Trial. Anesth Analg. 2015;121(2):348-356.

90. Kim YR, Choi JW, Sim WS, Lee CJ, Chang C. The influence of patient position on withdrawal force of lumbar epidural catheters after total knee arthroplasty: A randomized trial. J Clin Anesth. 2016;34:98-104.

91. Anell-Olofsson M, Lönnqvist PA, Bitkover C, et al. Plasma concentrations of levobupivacaine associated with two different intermittent wound infusion regimens following surgical ductus ligation in preterm infants. Paediatr Anaesth. 2015;25(7):711-718.

92. Tuncali B, Boya H, Arac S. Caudal block combined with propofol infusion using laryngeal mask airway in a spontaneously ventilating child with merosin-positive occidental type congenital muscular dystrophy. J Clin Anesth. 2016;32:196-197.

93. Kharabish A, Mkrtchyan N, Meierhofer C, et al. Cardiovascular magnetic resonance is successfully feasible in many patients aged 3 to 8years without general anesthesia or sedation. J Clin Anesth 2016;34:11-14.

94. Aysenur D, Mine C, Ozgur Y, et al. Pre-emptive peritonsillar dexamethasone vs. levobupivacaine infiltration for relief of post-adenotonsillectomy pain in children: a controlled clinical study. Int J Pediatr Otorhinolaryngol. 2014;78(9):1467-1471.

95. El-Shmaa NS, El-Baradey GF. The efficacy of labetalol vs dexmedetomidine for attenuation of hemodynamic stress response to laryngoscopy and endotracheal intubation. J Clin Anesth. 2016;31: 267-273.

96. Anıl A, Kaya FN, Yavaşcaoğlu B, Mercanoğlu Efe E, Türker G, Demirci A. Comparison of postoperative analgesic efficacy of intraoperative single-dose intravenous administration of dexketoprofen trometamol and diclofenac sodium in laparoscopic cholecystectomy. J Clin Anesth. 2016;32:127-133.

97. Fares KM, Othman AH, Alieldin NH. Efficacy and safety of dexmedetomidine added to caudal bupivacaine in pediatric major abdominal cancer surgery. Pain Physician. 2014;17(5):393-400.
98. Bharti N, Praveen R, Bala I. A dose-response study of caudal dexmedetomidine with ropivacaine in pediatric day care patients undergoing lower abdominal and perineal surgeries: a randomized controlled trial. Paediatr Anaesth. 2014;24(11):1158-1163.

99. Chen Y, Xie Y, Xue Y, Wang B, Jin X. Effects of ultrasound-guided stellate ganglion block on autonomic nervous function during $\mathrm{CO} 2$ pneumoperitoneum: A randomized double-blind control trial. J Clin Anesth. 2016;32:255-261.

100. Disma N, Mameli L, Pistorio A, et al. A novel balanced isotonic sodium solution vs normal saline during major surgery in children up to 36 months: a multicenter RCT. Paediatr Anaesth. 2014;24(9):980-986.

101. Khanna A, Saxena R, Dutta A, Ganguly N, Sood J. Comparison of ropivacaine with and without fentanyl vs bupivacaine with fentanyl for postoperative epidural analgesia in bilateral total knee replacement surgery. J Clin Anesth. 2017;37:7-13.

102. Pestieau SR, Finkel JC, Junqueira MM, et al. Prolonged perioperative infusion of low-dose ketamine does not alter opioid use after pediatric scoliosis surgery. Paediatr Anaesth. 2014;24(6):582-590.

103. Harbell MW, Cohen JM, Kolodzie K, et al. Combined preoperative femoral and sciatic nerve blockade improves analgesia after anterior cruciate ligament reconstruction: a randomized controlled clinical trial. J Clin Anesth. 2016;33:68-74.

104. Kakkar A, Tyagi A, Nabi N, Sethi AK, Verma UC. Comparision of clonidine and dexmedetomidine for attenuation of laryngoscopy and intubation response - A randomized controlled trial. J Clin Anesth. 2016;33:283-288.

105. Lukosiene L, Rugyte DC, Macas A, Kalibatiene L, Malcius D, Barauskas V. Postoperative pain management in pediatric patients undergoing minimally invasive repair of pectus excavatum: the role of intercostal block. J Pediatr Surg. 2013;48(12):2425-2430.

106. Oppermann J, Bredow J, Spies CK, et al. Effect of prolonged-released oxycodone/naloxone in postoperative pain management after total knee replacement: a nonrandomized prospective trial. J Clin Anesth. 2016;33:491-497.

107. Sethi S, Ghai B, Sen I, Ram J, Wig J. Efficacy of subtenon block in infants - a comparison with intravenous fentanyl for perioperative analgesia in infantile cataract surgery. Paediatr Anaesth. 2013;23(11):1015-1020.

108. Ozer AB, Karatepe U, Yildiz Altun A, Bolat E. Anesthesia-airway management in a newborn with syngnathia. J Clin Anesth. 2016;34:615.

109. Ortiz MP, Godoy MC, Schlosser RS, et al. Effect of endovenous lidocaine on analgesia and serum cytokines: double-blinded and randomized trial. J Clin Anesth. 2016;35:70-77.

110. Børglum J, Johansen K, Christensen MD, et al. Ultrasound-guided single-penetration dual-injection block for leg and foot surgery: a prospective, randomized, double-blind study. Reg Anesth Pain Med. 2014;39(1):18-25.

111. Templeton TW, Hoke LK, Templeton LB, Ririe DG, Rose DM, Bryan YF. A comparison of 3 ventilation strategies in children younger than 1 year using a Proseal laryngeal mask airway: a randomized controlled trial. J Clin Anesth. 2016;35:502-508.

112. Ozkan D, Akkaya T, Karakoyunlu N, et al. Effect of ultrasound-guided intercostal nerve block on postoperative pain after percutaneous nephrolithotomy : prospective randomized controlled study. Anaesthesist 2013;62(12):988-994.

113. Xu H, Li H, Zuo Y, et al. A multicenter study of the analgesic effects of epidural chloroprocaine after lower limb orthopedic surgery. J Clin Anesth. 2016;35:313-320.

114. She YJ, Xie GT, Tan YH, et al. A prospective study comparing the onset and analgesic efficacy of different concentrations of levobupivacaine with/without dexmedetomidine in young children undergoing caudal blockade. J Clin Anesth. 2015;27(1):17-22.

115. Li JY, Liao R. Dorsal penile nerve block with ropivacaine versus intravenous tramadol for the prevention of catheter-related bladder discomfort: study protocol for a randomized controlled trial. Trials. 2015;16:596. 
116. Davidson AJ, Morton NS, Arnup SJ, et al. Apnea after Awake Regional and General Anesthesia in Infants: The General Anesthesia Compared to Spinal Anesthesia Study--Comparing Apnea and Neurodevelopmental Outcomes, a Randomized Controlled Trial. Anesthesiology. 2015;123(1):38-54.

117. Wang H, Liu G, Fu W, Li ST. The effect of infraorbital nerve block on emergence agitation in children undergoing cleft lip surgery under general anesthesia with sevoflurane. Paediatr Anaesth. 2015;25(9):906-910.

118. Bareka M, Hantes M, Arnaoutoglou E, Vretzakis G. Superior perioperative analgesia with combined femoral-obturator-sciatic nerve block in comparison with posterior lumbar plexus and sciatic nerve block for ACL reconstructive surgery. Knee Surg Sports Traumatol Arthrosc. 2018;26(2):478-484.

119. Sort R, Brorson S, Gögenur I, Møller AM. AnAnkle Trial study protocol: a randomised trial comparing pain profiles after peripheral nerve block or spinal anaesthesia for ankle fracture surgery. BMJ Open. 2017;7(5): e016001.

120. Hou YY, LiY, He SF, et al. Effects of differential-phase remote ischemic preconditioning intervention in laparoscopic partial nephrectomy: A single blinded, randomized controlled trial in a parallel group design. J Clin Anesth. 2017;41:21-28.

121. Erdogan MA, Ozgul U, Uçar M, et al. Effect of transversus abdominis plane block in combination with general anesthesia on perioperative opioid consumption, hemodynamics, and recovery in living liver donors: The prospective, double-blinded, randomized study. Clin Transplant. 2017;31(4):e12931.

122. Tammam TF, Salama AF. Laparoscopic-guided psoas blockade as a novel analgesic method during inguinal herniorrhaphy: a clinical trial. Acta Anaesthesiol Scand. 2017;61(2):232-240.

123. Ishio J, Komasawa N, Kido H, Minami T. Evaluation of ultrasoundguided posterior quadratus lumborum block for postoperative analgesia after laparoscopic gynecologic surgery. J Clin Anesth. 2017;41:1-4.

124. Krishnan SH, Gilbert LA, Ghoddoussi F, Applefield DJ, Kassab SS, Ellis TA. Addition of buprenorphine to local anesthetic in adductor canal blocks after total knee arthroplasty improves postoperative pain relief: a randomized controlled trial. J Clin Anesth. 2016;33:432-437.

125. Büttner B, Mansur A, Hinz J, Erlenwein J, Bauer M, Bergmann I. Combination of general anesthesia and peripheral nerve block with low-dose ropivacaine reduces postoperative pain for several days after outpatient arthroscopy: A randomized controlled clinical trial. Medicine. 2017;96(6):e6046

126. Stasiowski MJ, Kolny M, Zuber M, et al. Randomised controlled trial of analgesic effectiveness of three different techniques of single-shot interscalene brachial plexus block using $20 \mathrm{~mL}$ of $0.5 \%$ ropivacaine for shoulder arthroscopy. Anestezjol Intens Ter. 2017;49(3): 215-221.

127. Sakae TM, Marchioro P, Schuelter-Trevisol F, Trevisol DJ. Dexamethasone as a ropivacaine adjuvant for ultrasound-guided interscalene brachial plexus block: A randomized, double-blinded clinical trial. J Clin Anesth. 2017;38:133-136.

128. Bali C, Ozmete O, Eker HE, Hersekli MA, Aribogan A. Postoperative analgesic efficacy of fascia iliaca block versus periarticular injection for total knee arthroplasty. J Clin Anesth. 2016;35:404-410.

129. Kolny M, Stasiowski MJ, Zuber M, et al. Randomized, comparative study of the effectiveness of three different techniques of interscalene brachial plexus block using $0.5 \%$ ropivacaine for shoulder arthroscopy. Anestezjol Intens Ter. 2017;49(1):47-52.

130. El Sherif FA, Mohamed SA, Kamal SM. The effect of morphine added to bupivacaine in ultrasound guided transversus abdominis plane (TAP) block for postoperative analgesia following lower abdominal cancer surgery, a randomized controlled study. J Clin Anesth. 2017;39:4-9.

131. Harbell MW, Cohen JM, Kolodzie K, et al. Combined preoperative femoral and sciatic nerve blockade improves analgesia after anterior cruciate ligament reconstruction: a randomized controlled clinical trial. J Clin Anesth. 2016;33:68-74.

132. Aliste J, Leurcharusmee P, Engsusophon P, et al. A randomized comparison between intravenous and perineural dexamethasone for ultrasound-guided axillary block. Can J Anaesth. 2017;64(1):29-36.
133. Choi YM, Byeon GJ, Park SJ, Ok YM, Shin SW, Yang K. Postoperative analgesic efficacy of single-shot and continuous transversus abdominis plane block after laparoscopic cholecystectomy: A randomized controlled clinical trial. J Clin Anesth. 2017;39:146-151.

134. Madabushi R, Rajappa GC, Thammanna PP, Iyer SS. Fascia iliaca block vs intravenous fentanyl as an analgesic technique before positioning for spinal anesthesia in patients undergoing surgery for femur fractures-a randomized trial. J Clin Anesth. 2016;35:398-403.

135. Pere P, Harju J, Kairaluoma P, Remes V, Turunen P, Rosenberg PH. Randomized comparison of the feasibility of three anesthetic techniques for day-case open inguinal hernia repair. J Clin Anesth. 2016;34:166-175.

136. Bang SU, Kim DJ, Bae JH, Chung K, Kim Y. Minimum effective local anesthetic volume for surgical anesthesia by subparaneural, ultrasoundguided popliteal sciatic nerve block: A prospective dose-finding study. Medicine. 2016;95(34):e4652.

137. Oksar M, Koyuncu O, Turhanoglu S, Temiz M, Oran MC. Transversus abdominis plane block as a component of multimodal analgesia for laparoscopic cholecystectomy. J Clin Anesth. 2016;34:72-78.

138. Lam NC, Baker EB, Fishburn SJ, Hammer AR, Petersen TR, Mariano ER. A Randomized Double-Blinded Trial on the Effects of Ultrasound Transducer Orientation on Teaching and Learning Ultrasound-Guided Regional Anesthesia. J Ultrasound Med. 2016;35(7):1509-1516.

139. Lim HJ, Hasan MS, Chinna K. Faster onset time of supraclavicular brachial plexus block using local anesthetic diluted with dextrose. Braz J Anesthesiol. 2016;66(4):341-345.

140. Arora S, Chhabra A, Subramaniam R, Arora MK, Misra MC, Bansal VK. Transversus abdominis plane block for laparoscopic inguinal hernia repair: a randomized trial. J Clin Anesth. 2016;33:357-364.

141. Ömür D, Oğuzalp H, Kiraz HA, et al. The analgesic efficacy of ultrasound-guided transversus abdominis plane block on postoperative pain and morphine consumption in varicocelectomy. Saudi Med J. 2016;37(6):648-655.

142. Fusco P, Cofini V, Petrucci E, et al. Unilateral paravertebral block compared with subarachnoid anesthesia for the management of postoperative pain syndrome after inguinal herniorrhaphy: a randomized controlled clinical trial. Pain. 2016;157(5):1105-1113.

143. Erdoğan Arı D, Yıldırım Ar A, Karadoğan F, et al. Ultrasound-guided transversus abdominis plane block in patients undergoing open inguinal hernia repair: $0.125 \%$ bupivacaine provides similar analgesic effect compared to $0.25 \%$ bupivacaine. J Clin Anesth. 2016;28:41-46.

144. Jeong JS, Shim JC, Shim JH, Han KH. A comparison of motor stimulation threshold in ultrasound-guided interscalene brachial plexus block for arthroscopic shoulder surgery: a randomized trial. Can J Anaesth. 2016;63(4):461-467.

145. Ambrosoli AL, Chiaranda M, Fedele LL, Gemma M, Cedrati V, Cappelleri G. A randomised controlled trial of intrathecal blockade versus peripheral nerve blockade for day-case knee arthroscopy. Anaesthesia. 2016;71(3):280-284.

146. Kasimahanti R, Arora S, Bhatia N, Singh G. Ultrasound-guided single- vs double-level thoracic paravertebral block for postoperative analgesia in total mastectomy with axillary clearance. J Clin Anesth. 2016;33:414-421.

147. Stundner O, Meissnitzer M, Brummett CM, et al. Comparison of tissue distribution, phrenic nerve involvement, and epidural spread in standard-vs low-volume ultrasound-guided interscalene plexus block using contrast magnetic resonance imaging: a randomized, controlled trial. Br J Anaesth. 2016;116(3):405-412.

148. Versyck B, van Geffen GJ, van Houwe P. Prospective double blind randomized placebo-controlled clinical trial of the pectoral nerves (Pecs) block type II. J Clin Anesth. 2017;40:46-50.

149. Mouzi LK, Adams O, Cuff G, Lukasiewicz E, Champeil E, Atchabahian A. Plasma concentrations of ropivacaine following ultrasound-guided or nerve-stimulator-guided femoral nerve block: A prospective randomised study. Anaesth Crit Care Pain Med. 2016;35(1):45-48.

150. Cegin MB, Soyoral L, Yuzkat N, Baydi V, Goktas U. Pregabalin administered as an anxiolytic agent in ultrasound-guided infraclavicular block: a controlled, double-blind, dose-ranging trial. Eur Rev Med Pharmacol Sci. 2016;20(3):568-574. 
151. Chen Y, Xie Y, Xue Y, Wang B, Jin X. Effects of ultrasound-guided stellate ganglion block on autonomic nervous function during $\mathrm{CO} 2$ pneumoperitoneum: A randomized double-blind control trial. J Clin Anesth. 2016;32:255-261.

152. Ueshima H, Otake H. Clinical experiences of ultrasound-guided lateral thoracolumbar Interfascial plane (TLIP) block. J Clin Anesth. 2017;39:145

153. Jin F, Li XQ, Tan WF, Ma H, Lu HW. Preoperative versus postoperative ultrasound-guided rectus sheath block for improving pain, sleep quality and cytokine levels of patients with open midline incisions undergoing transabdominal gynaecological operation: study protocol for a randomised controlled trial. Trials. 2015;16(1):568.

154. Walker BJ. What's in a dose? Advantages and disadvantages of reducing local anesthetic requirements in children. $J$ Clin Anesth. 2017;38:158-159.

155. Freiermuth D, Kretzschmar M, Bilecen D, et al. Correlation of $(99 \mathrm{~m})$ Tc-DPD SPECT/CT Scan Findings and Diagnostic Blockades of Lumbar Medial Branches in Patients with Unspecific Low Back Pain in a Randomized-Controlled Trial. Pain Med. 2015;16(10):1916-1922.

156. Abouammoh MA, Abdelhalim AA, Mohamed EA, Elzoughari I, Mustafa M, Al-Zahrani TA. Subtenon block combined with general anesthesia for vitreoretinal surgery improves postoperative analgesia in adult: a randomized controlled trial. J Clin Anesth . 2016;30:78-86.

157. Hotujec BT, Spencer RJ, Donnelly MJ, et al. Transversus abdominis plane block in robotic gynecologic oncology: A randomized, placebocontrolled trial. Gynecol Oncol. 2015;136(3):460-465.

158. Yamamoto H, Sakura S, Wada M, Shido A. A prospective, randomized comparison between single- and multiple-injection techniques for ultrasound-guided subgluteal sciatic nerve block. Anesth Analg 2014;119(6):1442-1448.

159. Ueshima H, Shimazaki A, Otake H. Cervical plexus block for perioperative analgesia during otoplasty. J Clin Anesth. 2017;38:71.

160. O'Sullivan O, Iohom G, O'Donnell BD, Shorten GD. The effect of simulation-based training on initial performance of ultrasound-guided axillary brachial plexus blockade in a clinical setting - a pilot study. BMC Anesthesiol. 2014;14(1):110.

161. Kumar N, Thapa D, Gombar S, Ahuja V, Gupta R. Analgesic efficacy of pre-operative stellate ganglion block on postoperative pain relief: a randomised controlled trial. Anaesthesia. 2014;69(9):954-660.

162. Ueshima H, Hiroshi O. Clinical experiences of Ultrasound-guided transversus thoracic muscle plane block for children. J Clin Anesth. 2017; 40:23.

163. Farag E, Atim A, Ghosh R, et al. Comparison of three techniques for ultrasound-guided femoral nerve catheter insertion: a randomized, blinded trial. Anesthesiology. 2014;121(2):239-248.

164. Tammam TF. Ultrasound-guided sciatic nerve block: a comparison between four different infragluteal probe and needle alignment approaches. J Anesth. 2014;28(4):532-537.

165. Marhofer D, Karmakar MK, Marhofer P, Kettner SC, Weber M, Zeitlinger M. Does circumferential spread of local anaesthetic improve the success of peripheral nerve block? Br J Anaesth. 2014;113(1): $177-185$.

166. de Oliveira GS, Bialek J, Rodes ME, Kendall MC, Mccarthy RJ. The effect of sevoflurane compared to propofol maintenance on postsurgical quality of recovery in patients undergoing an ambulatory gynecological surgery: A prospective, randomized, double-blinded, controlled, clinical trial. J Clin Anesth. 2017;43:70-74.

167. Schmutz M, Schumacher PM, Luyet C, Curatolo M, Eichenberger U. Ilioinguinal and iliohypogastric nerves cannot be selectively blocked by using ultrasound guidance: a volunteer study. Br J Anaesth. 2013;111(2):264-270.

168. Dingeman RS, Barus LM, Chung HK, et al. Ultrasonography-guided bilateral rectus sheath block vs local anesthetic infiltration after pediatric umbilical hernia repair: a prospective randomized clinical trial JAMA Surg. 2013;148(8):707-713.
169. Landsem LM, Ross FJ, Eisses MJ. A case of midazolam anaphylaxis during a pediatric patient's first anesthetic. J Clin Anesth. 2017:43:75-76.

170. Lorenzo AJ, Lynch J, Matava C, El-Beheiry H, Hayes J. Ultrasound guided transversus abdominis plane vs surgeon administered intraoperative regional field infiltration with bupivacaine for early postoperative pain control in children undergoing open pyeloplasty. $J$ Urol. 2014;192(1):207-213.

171. Albrecht E, Kirkham KR, Endersby RV, et al. Ultrasound-guided transversus abdominis plane (TAP) block for laparoscopic gastricbypass surgery: a prospective randomized controlled double-blinded trial. Obes Surg. 2013;23(8):1309-1314.

172. Ueshima H, Hara E, Marui T, Otake H. The ultrasound-guided transversus thoracic muscle plane block is effective for the median sternotomy J Clin Anesth. 2016;29:83.

173. Espelund M, Fomsgaard JS, Haraszuk J, Mathiesen O, Dahl JB. Analgesic efficacy of ultrasound-guided adductor canal blockade after arthroscopic anterior cruciate ligament reconstruction: a randomised controlled trial. Eur J Anaesthesiol. 2013;30(7):422-428.

174. Wu X, Jiang Z, Ying J, Han Y, Chen Z. Optimal blood pressure decreases acute kidney injury after gastrointestinal surgery in elderly hypertensive patients: A randomized study: Optimal blood pressure reduces acute kidney injury. J Clin Anesth. 2017;43: 77-83.

175. Petersen PL, Mathiesen O, Stjernholm P, et al. The effect of transversus abdominis plane block or local anaesthetic infiltration in inguinal hernia repair: a randomised clinical trial. Eur JAnaesthesiol. 2013;30(7):415-421.

176. Hidas G, Kelly MS, Watts B, Kain ZN, Khoury AE. Application of continuous incisional infusion of local anesthetic after major pediatric urological surgery: prospective randomized controlled trial. J Pediatr Surg. 2015;50(3):481-484.

177. Hattori K, Komasawa N, Kuzukawa Y, Fujisawa T, Minami T. Right radial artery pulse loss after transesophageal echocardiography probe insertion in an infant with an aberrant right subclavian artery. J Clin Anesth. 2016;28:84.

178. Yamada K, Inomata S, Tanaka M. The Ropivacaine Concentration Required for Ultrasound-Guided Ilioinguinal/Iliohypogastric Nerve Block in Pediatric Patients. Anesth Analg. 2016;123(1):175-178.

179. Hall Burton DM, Boretsky KR. A comparison of paravertebral nerve block catheters and thoracic epidural catheters for postoperative analgesia following the Nuss procedure for pectus excavatum repair. Paediatr Anaesth. 2014;24(5):516-520.

180. Giraldes AL, Sousa AM, Slullitel A, et al. Tramadol wound infiltration is not different from intravenous tramadol in children: a randomized controlled trial. J Clin Anesth. 2016;28:62-66.

181. Weiss JE, Haines KA, Chalom EC, et al. A randomized study of local anesthesia for pain control during intra-articular corticosteroid injection in children with arthritis. Pediatr Rheumatol Online J. 2015;13(1):36.

182. Hayaran N, Sardana R, Nandinie H, Jain A. Unusual presentation of local anesthetic toxicity. J Clin Anesth. 2017;36:36-38.

183. Elbay M, Ü Şermet Elbay, Yıldırım S, Uğurluel C, Kaya C, Baydemir C. Comparison of injection pain caused by the DentalVibe Injection System versus a traditional syringe for inferior alveolar nerve block anaesthesia in paediatric patients. Eur J Paediatr Dent. 2015;16(2):123-128.

184. Haghighat A, Jafari Z, Hasheminia D, Samandari MH, Safarian V, Davoudi A. Comparison of success rate and onset time of two different anesthesia techniques. Med Oral Patol Oral Cir Bucal. 2015;20(4):e459-e463.

185. Conner ER, Musser ED, Colpitts KM, Laochamroonvorapongse DL, Koh JL. Perioperative opioid administration in children with and without developmental delay undergoing outpatient dental surgery. $J$ Clin Anesth. 2017;37:92-96. 
186. Alamoudi NM, Baghlaf KK, Elashiry EA, Farsi NM, El Derwi DA, Bayoumi AM. The effectiveness of computerized anesthesia in primary mandibular molar pulpotomy: A randomized controlled trial. Quintessence Int. 2016;47(3):217-224.

187. Torii N, Tachibana K, Iwasaki M, Takeuchi M, Kinouchi K. Ultrasound-guided Rectus Sheath Block vs Transversus Abdominis Plane Block in Children Undergoing Umbilical Hernia Repair. Masui. 2016;65(6):560-565

188. Nan Y, Zhou J, Ma Q, Li T, Lian QQ, Li J. Application of ultrasound guidance for ilioinguinal or iliohypogastric nerve block in pediatric inguinal surgery. Zhonghua Yi Xue Za Zhi. 2012;92(13):873-877.

189. Yang S, Song Z, Gau Q. Efficacy of different methods of anesthesia on children underwent hypospadias surgery. Zhong Nan Da Xue Xue Bao Yi Xue Ban. 2015;40(9):1008-1011.

190. Reena BKH, Bandyopadhyay K, Paul A. Postoperative analgesia for cleft lip and palate repair in children. JAnaesthesiol Clin Pharmacol. 2016;32(1):5-11.

191. Öksüz G, Urfalığlu A, Bilal B, Arslan M. Anaesthetic management of a patient with Michels syndrome. J Clin Anesth. 2017;38:20-21.

192. Stewart DW, Ragg PG, Sheppard S, Chalkiadis GA. The severity and duration of postoperative pain and analgesia requirements in children after tonsillectomy, orchidopexy, or inguinal hernia repair. Paediatr Anaesth. 2012;22(2):136-143.

193. Oh J, Perlas A, Lau J, Gandhi R, Chan VW. Functional outcome and cost-effectiveness of outpatient vs inpatient care for complex hindfoot and ankle surgery. A retrospective cohort study. J Clin Anesth. 2016;35:20-25.

194. Boezaart AP, Wright TW. Rational use and pitfalls of regional anesthesia for orthopedic surgery. Tech Orthop. 2017;32(4):209-216.

195. Ohsfeldt RL, Miller TR, Schneider JE, Scheibling CM. Cost impact of unexpected disposition after orthopedic ambulatory surgery associated with category of anesthesia provider. J Clin Anesth. 2016;35: 157-162.

196. Malviya S, Voepel-Lewis T, Burke C, Merkel S, Tait AR. The revised FLACC observational pain tool: improved reliability and validity for pain assessment in children with cognitive impairment. Paediatr Anaesth. 2006;16(3):258-265.

197. Grosen K, Pfeiffer-Jensen M, Pilegaard HK. Postoperative consumption of opioid analgesics following correction of pectus excavatum is influenced by pectus severity: a single-centre study of 236 patients undergoing minimally invasive correction of pectus excavatum. Eur J Cardiothorac Surg. 2010;37(4):833-839.

198. Coln D, Gunning T, Ramsay M, et al. Early experience with the Nuss minimally invasive correction of pectus excavatum in adults. World $J$ Surg. 2002;26(10):1217-1221.

199. St Peter SD, Weesner KA, Sharp RJ, et al. Is epidural anesthesia truly the best pain management strategy after minimally invasive pectus excavatum repair? J Pediatr Surg. 2008;43(1):79-82.

200. Beeton ML. Possible missed diagnosis of Ureaplasma spp infection in a case of fatal hyperammonemia after repeat renal transplantation. J Clin Anesth. 2016;33:504-505.

201. Dean M. Opioids in renal failure and dialysis patients. J Pain Symptom Manage. 2004;28(5):497-504.

202. Schaff J, Maniker R. Anesthetic management of donor nephrectomy for a recipient with history of malignant hyperthermia: avoiding a transferred trigger. J Clin Anesth. 2016;31:259-262.

203. Gunter JB, Eng C. Thoracic epidural anesthesia via the caudal approach in children. Anesthesiology. 1992;76(6):935-938
204. Kasai T, Yaegashi K, Hirose M, Tanaka Y. Spinal cord injury in a child caused by an accidental dural puncture with a single-shot thoracic epidural needle. Anesth Analg. 2003;96(1):65-67.

205. Blanc VF, Hardy JF, Milot J, Jacob JL. The oculocardiac reflex: a graphic and statistical analysis in infants and children. Can Anaesth Soc J. 1983;30(4):360-369.

206. Shick V, Lebovitz EE, Conrad E. The benefits of ultrasound-guided continuous sensory nerve blockade in the setting of burn injury: a case report of bilateral continuous superficial peroneal nerve blockade in a patient with severe sleep apnea. J Clin Anesth. 2017;36:62-66.

207. Sanjay P, Woodward A. Inguinal hernia repair: local or general anaesthesia? Ann R Coll Surg Engl. 2007;89(5):497-503.

208. Eppstein AC, Sakamoto B. The novel use of different bupivacaine preparations with combined regional techniques for postoperative pain management in non-opioid-based laparoscopic inguinal herniorrhaphy. J Clin Anesth. 2016;34:403-406.

209. Pere P, Harju J, Kairaluoma P, Remes V, Turunen P, Rosenberg PH. Randomized comparison of the feasibility of three anesthetic techniques for day-case open inguinal hernia repair. J Clin Anesth. 2016;34:166-175.

210. Paleczny J, Zipser P, Pysz M. Paravertebral block for open cholecystectomy. Anestezjol Intens Ter. 2009;41(2):89-93.

211. Longo MA, Cavalheiro BT, de Oliveira Filho GR. Laparoscopic cholecystectomy under neuraxial anesthesia compared with general anesthesia: Systematic review and meta-analyses. J Clin Anesth. 2017;41:48-54.

212. Naja MZ, Ziade MF, Lönnqvist PA. General anaesthesia combined with bilateral paravertebral blockade (T5-6) vs. general anaesthesia for laparoscopic cholecystectomy: a prospective, randomized clinical trial. Eur J Anaesthesiol. 2004;21(6):489-495.

213. Dalens B, Hasnaoui A. Caudal anesthesia in pediatric surgery: success rate and adverse effects in 750 consecutive patients. Anesth Analg. 1989;68(2):83-89.

214. Hong JY, Han SW, Kim WO, Kim EJ, Kil HK. Effect of dexamethasone in combination with caudal analgesia on postoperative pain control in day-case paediatric orchiopexy. Br J Anaesth. 2010;105(4):506-510.

215. Dube P, Mitra S, Singh J, Saroa R, Mehra R. Intravenous dexamethasone as an adjunct to improve labor analgesia: A randomized, doubleblinded, placebo controlled clinical trial. J Clin Anesth. 2017;43:6-10.

216. Pehora C, Pearson AM, Kaushal A, Crawford MW, Johnston B. Dexamethasone as an adjuvant to peripheral nerve block. Cochrane Database Syst Rev. 2017;11:CD011770.

217. Kirksey MA, Haskins SC, Cheng J, Liu SS. Local Anesthetic Peripheral Nerve Block Adjuvants for Prolongation of Analgesia: A Systematic Qualitative Review. PLoS One. 2015;10(9):e0137312.

218. Sanchez Munoz MC, de Kock M, Forget P. What is the place of clonidine in anesthesia? Systematic review and meta-analyses of randomized controlled trials. J Clin Anesth. 2017;38:140-153.

219. Joshi G, Gandhi K, Shah N, Gadsden J, Corman SL. Peripheral nerve blocks in the management of postoperative pain: challenges and opportunities. J Clin Anesth. 2016;35:524-529.

220. Ahn EJ, Park JH, Kim HJ, Kim KW, Choi HR, Bang SR. Anticholinergic premedication to prevent bradycardia in combined spinal anesthesia and dexmedetomidine sedation: a randomized, double-blind, placebo-controlled study. J Clin Anesth. 2016;35:13-19.

221. Lee-Archer P, Mcbride C, Paterson R, Reade M, Regli-von UngernSternberg B, Long D. Does dexmedetomidine given as a premedication or intraoperatively reduce post-hospitalisation behaviour change in children? A study protocol for a randomised controlled trial in a tertiary paediatric hospital. BMJ Open. 2018;8(4):e019915. 


\section{Publish your work in this journal}

Local and Regional Anesthesia is an international, peer-reviewed, open access journal publishing on the development, pharmacology, delivery and targeting and clinical use of local and regional anesthetics and analgesics. The journal is included in PubMed, and welcomes submitted papers covering original research, basic science, clinical studies, reviews and evaluations, guidelines, expert opinion and commentary, case reports and extended reports. The manuscript management system is completely online and includes a very quick and fair peer-review system, which is all easy to use. Visit http://www.dovepress.com/ testimonials.php to read real quotes from published authors.

Submit your manuscript here: https://www.dovepress.com/local-and-regional-anesthesia-journal 